\title{
Update of Legacy NIST Horizontal Micro-Fin Tube Convective Boiling Measurements and Model with Current Fluid Property Values
}

Mark A. Kedzierski

Lingnan Lin

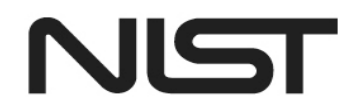




\title{
Update of Legacy NIST Horizontal Micro-Fin Tube Convective Boiling Measurements and Model with Current Fluid Property Values
}

\author{
Mark A. Kedzierski \\ Lingnan Lin \\ Energy and Environment Division \\ Engineering Laboratory
}

This publication is available free of charge from:

https://doi.org/10.6028/NIST.TN.2179

November 2021

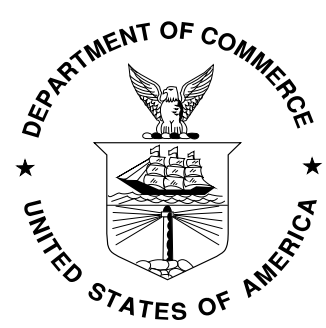

U.S. Department of Commerce

Gina M. Raimondo, Secretary

National Institute of Standards and Technology James K. Olthoff, Performing the Non-Exclusive Functions and Duties of the Under Secretary of Commerce for Standards and Technology \& Director, National Institute of Standards and Technology 
Certain commercial entities, equipment, or materials may be identified in this document in order to describe an experimental procedure or concept adequately. Such identification is not intended to imply recommendation or endorsement by the National Institute of Standards and Technology, nor is it intended to imply that the entities, materials, or equipment are necessarily the best available for the purpose.

National Institute of Standards and Technology Technical Note 2179 Natl. Inst. Stand. Technol. Tech. Note 2179, 42 pages (November 2021) CODEN: NTNOEF

This publication is available free of charge from: https://doi.org/10.6028/NIST.TN.2179 


\title{
Update of Legacy NIST Horizontal Micro-Fin Tube Convective Boiling Measurements and Model with Current Fluid Property Values
}

M. A. Kedzierski and L. Lin

National Institute of Standards and Technology

Gaithersburg, MD 20899

\begin{abstract}
This report presents local convective boiling heat transfer measurements in a micro-fin tube for twenty refrigerants taken between the years 1996 and 2021. All of the measurements were taken at the Two-Phase Heat Transfer Laboratory at the National Institute of Standards and Technology (NIST). The same test section was used throughout the years, which was heated with water in either counterflow or in parallel flow with the test refrigerant to provide for a range of heat fluxes for each thermodynamic quality. The heat transfer measurements were re-reduced while using the current properties for the test refrigerants. The reevaluation of the measured Nusselt numbers resulted in as large as a $40 \%$ correction for mixed refrigerants and no correction for recently published measurements. A new correlation was developed for the NIST dataset, which included both single and multi-component mixtures, to account for the updated fluid properties and to provide a single model for the large dataset. The correlation predicted the measurements to within $\pm 6.8 \%$ for single components and $12.3 \%$ for mixtures. A website with the corrected measurements was established and is available for download.
\end{abstract}

Keywords: boiling, enhanced heat transfer, low-GWP, micro-fin, refrigerant mixtures 
Table of Contents

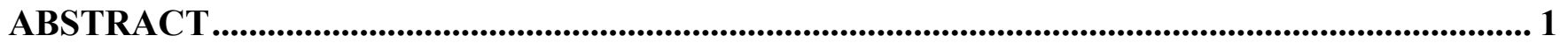

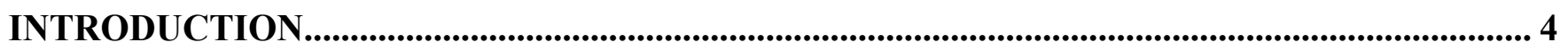

EXPERIMENTAL APPARATUS................................................................................................. 5

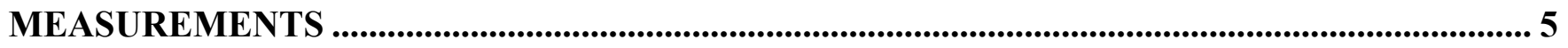

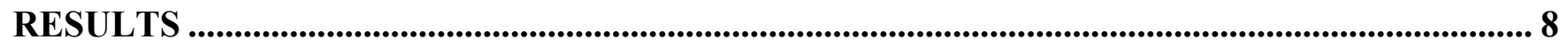

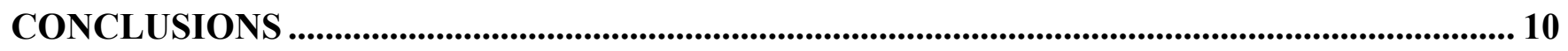

ACKNOWLEDGEMENTS ................................................................................................................ 10

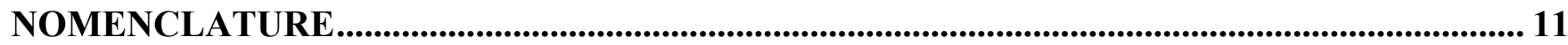

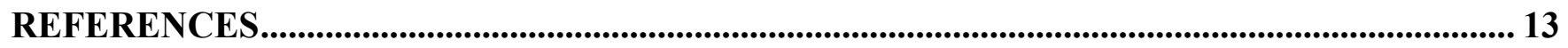

Figure 1 Schematic of test rig showing counterflow arrangement........................................................... 15

Figure 2 Test section cross section............................................................................................................... 16

Figure 3 Detailed schematic of test section (counterflow)......................................................................... 17

Figure 4 Counterflow temperature profiles for a R1234yf test .................................................................. 18

Figure 5 Heat flux distribution for R134a .............................................................................................. 19

Figure 6 Comparison between measured Nusselt numbers and those predicted by eq. (4) ............ 20

Figure 7 Comparison between measured Nusselt numbers and those predicted by eq. (5) ............ 21

Figure 8 Comparison between measured Nusselt numbers and those predicted by eq. (4) for R22

Figure 9 Comparison between measured Nusselt numbers and those predicted by eq. (4) for R32

Figure 10 Comparison between measured Nusselt numbers and those predicted by eq. (4) for R125.............................................................................................................................................................. 24

Figure 11 Comparison between measured Nusselt numbers and those predicted by eq. (4) for R134a. 
Figure 12 Comparison between measured Nusselt numbers and those predicted by eq. (4) for

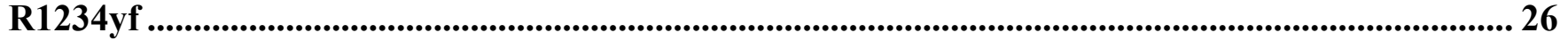

Figure 13 Comparison between measured Nusselt numbers and those predicted by eq. (4) for

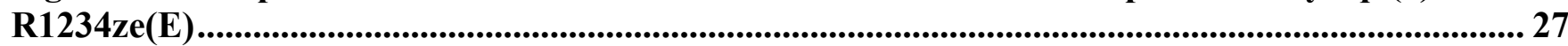

Figure 14 Comparison between measured Nusselt numbers and those predicted by eq. (5) for R407C

Figure 15 Comparison between measured Nusselt numbers and those predicted by eq. (5) for R410B

Figure 16 Comparison between measured Nusselt numbers and those predicted by eq. (5) for

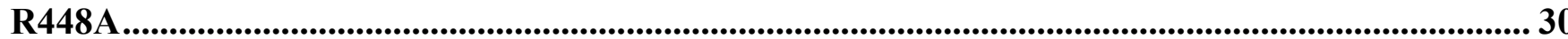

Figure 17 Comparison between measured Nusselt numbers and those predicted by eq. (5) for

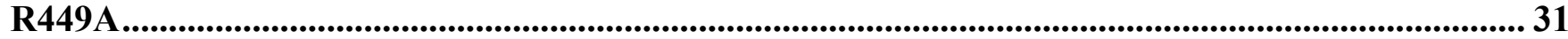

Figure 18 Comparison between measured Nusselt numbers and those predicted by eq. (5) for R450A.......................................................................................................................................................... 32

Figure 19 Comparison between measured Nusselt numbers and those predicted by eq. (5) for

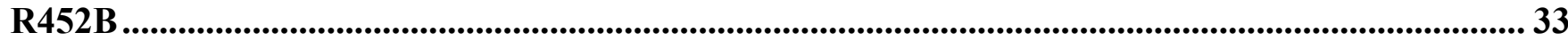

Figure 22 Comparison between measured Nusselt numbers and those predicted by eq. (5) for R32/R134a (27/73). 


\section{INTRODUCTION ${ }^{1}$}

The first micro-fin tube was probably developed around 1938 to solve the problem of dryout in water tube steam boilers (Bailey, 1942). Bailey's patent describes an invention for a tube with 53 internal fins approximately $0.38 \mathrm{~mm}$ tall rifling down the tube axis at a helix angle of $60^{\circ}$ with the purpose of inducing circumferential flow to maintain the liquid film on the upper portions of the tube wall. Because of the difficulty of mass production in copper, the commercial application of micro-fin tubes to refrigeration and air-conditioning did not occur until the early 1990's (Bogart, 2021). Since its commercial availability, the micro-fin tube has become the most popular internal enhancement for evaporators and condensers of new unitary refrigeration and air-conditioning equipment, primarily as a result of its highest heat transfer with the lowest pressure drop as compared to other enhancements (Webb and Kim, 2005). Consequently, flow boiling heat transfer data for the micro-fin tube with refrigerants are essential for the evaluation of their use for unitary applications.

For that last few decades, pressure from the policies set by the Montreal Protocol (1987) concerning ozone depletion potential (ODP), and the Kyoto Protocol (1997) and the European Mobile Directive (2006) for global warming potential (GWP) have caused a shift to refrigerants with both zero ODP and low GWP. Consequently, many of the flow boiling measurements for the micro-fin tube that have been made at the National Institute of Standards and Technology (NIST) are for the alternative refrigerants. As the new alternative refrigerants are developed, thermodynamic and transport properties must be developed for them. Throughout the years, earlier versions of NIST's REFPROP (Lemmon et al., 2018) have been used to reduce all of the NIST micro-fin flow boiling measurements. At times, the flow boiling measurements were made while only preliminary properties were available. The thermodynamic and transport properties are important for determining the thermodynamic quality, the saturation temperature, the non-dimensional numbers, and other parameters that are essential for reporting the measured and modeled micro-fin flow boiling heat transfer. Considering this, and the desire for accuracy, this paper re-reduces and models the NIST micro-fin boiling heat transfer measurements with the most recent thermodynamic and transport properties from REFPROP (Lemmon et al., 2018).

Flow boiling measurements for a micro-fin tube for mixed and single component refrigerants from five NIST studies, which all used the same test section, are presented here. Four of the studies contain data that was previously published and are reanalyzed here with current fluid properties. The first NIST study included here, by Hamilton et al. (2008), contains refrigerants R22, R32, R125, R134a, R32/R134a $(27 / 73)^{2}$, R32/R134a (30/70), R407C, and R410B. The second NIST study (Kedzierski and Park, 2013) contains the refrigerants R134a, R513A and R1234ze(E). The third NIST study (Kedzierski and Kang, 2016) contains the refrigerants R448A, R449A, and R452B. Finally, the fourth NIST study (Kedzierski and Kang, 2018) contains the refrigerants R1234yf, R134a, and R450A. The fifth study are measurements for R513A, R515B, and R450A that were analyzed with the current REFPROP and presented without the raw measurements in Domanski et al. (2021).

\footnotetext{
${ }^{1}$ Certain trade names and company products are mentioned in the text or identified in an illustration in order to adequately specify the experimental procedure and equipment used. In no case does such an identification imply recommendation or endorsement by the National Institute of Standards and Technology, nor does it imply that the products are necessarily the best available for the purpose.

2 All compositions are based on mass.
} 


\section{EXPERIMENTAL APPARATUS}

Considering that Kedzierski and Kang (2018) provide a detailed description of the test apparatus and the measurement technique, it will be briefly described here. Figure 1 shows a sketch of the experimental apparatus that was used in all five NIST studies to establish and measure convective boiling heat transfer coefficients. The experimental test facility consisted of two main systems: the refrigerant loop and the water loop. The refrigerant flow rate, pressure, and quality were fixed at the inlet to the test section. The water flow rate and the inlet temperature were fixed to establish the overall refrigerant quality change in the test section. The water temperature drop, the tube wall temperature, the refrigerant temperatures, pressures, and pressure drops were measured at several axial locations along the test section. These measurements were used to calculate the local heat-transfer coefficient for the micro-fin tube.

Figure 2 shows a cross section of the test section with a detail of the micro-fin tube geometry, which was the same for all four NIST studies. The test refrigerant flowed inside a micro-fin tube, while distilled water flowed either in parallel flow or counterflow to the refrigerant in the annulus that surrounded the micro-fin tube. Tests in both parallel flow and counterflow (as shown in Fig. 1) produced a broad range of heat fluxes at both low and high flow qualities. The annulus gap was $2.2 \mathrm{~mm}$, and the micro-fin tube wall thickness was $0.3 \mathrm{~mm}$. The micro fin tube had $60,0.2 \mathrm{~mm}$ high fins that rifled down the axis of the tube at a helix angle $(\alpha)$ of $18^{\circ}$ with respect to the tube axis. For this geometry, the cross sectional flow area was $60.8 \mathrm{~mm}^{2}$, giving an equivalent smooth diameter $\left(D_{e}\right)$ of $8.8 \mathrm{~mm}$. The root diameter of the micro-fin tube was $8.91 \mathrm{~mm}$. The inside-surface area per unit length of the tube was estimated to be $44.6 \mathrm{~mm}$. The hydraulic diameter $\left(D_{h}\right)$ was measured with a polar planimeter from a scaled drawing of the tube cross section and determined to be approximately $5.45 \mathrm{~mm}$. The ratio of the inner surface area of the micro fin tube to the surface area of a smooth tube of the same $D_{e}$ was 1.6.

Figure 3 provides a detailed schematic of the test section. Thermocouple wires pass between 12 of the gasketed flange pairs to measure the refrigerant-tube wall temperature at ten locations on the top, side, and bottom of the tube wall. Thermocouples were also mounted next to the pressure taps near the middle of each test section length. The thermocouple junction was soldered to the outside surface and was sanded to a thickness of approximately $0.5 \mathrm{~mm}$. The leads were strapped to a thin non-electrically-conducting epoxy layer on the wall for a distance of $14.3 \mathrm{~mm}$ before they passed between a pair of the shell flanges. The wall temperature was corrected for a heat flux dependent fin effect. The correction was typically $0.05 \mathrm{~K}$. Figure 3 also shows that a chain of ten-element thermopiles was used to measure the water temperature drop between each flange location.

As shown in Fig. 3, six refrigerant pressure taps along the test section allowed the measurement of the upstream absolute pressure and five pressure drops along the test section. Two sets of two water pressure taps were used to measure the water pressure drop along each tube. Also, a sheathed thermocouple measured the refrigerant temperature at each end of the two refrigerant tubes, with the junction of each centered radially. Only the thermocouple at the inlet of the first tube was used in the calculations. The entire test section was wrapped with $5 \mathrm{~cm}$ of foam insulation to minimize heat transfer between the water and the ambient.

\section{MEASUREMENTS}

NIST (2021) provides an online database that contains the complete corrected flow boiling heat transfer measurements of the Hamilton et al. (2008), the Kedzierski and Park (2013), the Kedzierski and Kang (2016), and the Kedzierski and Kang (2018). The data presented in Domanski et al. (2021) is also included 
in the database; however, it did not require correction. The online database shows the expanded measurement uncertainty $(U)$ of the various measurements along with the range of each test parameter in the four studies in Table 1 . The $U$ was estimated with the law of propagation of uncertainty. All expanded measurement uncertainties are reported at the $95 \%$ confidence level. The estimates shown in Table 1 are median values of $U$ for the correlated data. The average uncertainty, at the $95 \%$ confidence level, of the fitted wall temperatures for the counterflow and the parallel flow data was approximately $0.42 \mathrm{~K}$ and $0.36 \mathrm{~K}$, respectively. The median of the uncertainty in $T_{\mathrm{w}}$ as shown in Table 1 was approximately $0.4 \mathrm{~K}$. More detail for the uncertainties can be obtained from the original studies referenced above. The saturated refrigerant properties were re-evaluated at the measured saturation pressures with the REFPROP (Lemmon et al., 2018) equation of state. Table 2 in NIST (2021) shows representative properties that were obtained from REFPROP for all the test refrigerants evaluated at $277.6 \mathrm{~K}$.

The convective boiling heat transfer coefficient based on the actual inner surface area $\left(h_{2 \phi}\right)$ was calculated as:

$$
h_{2 \phi}=\frac{q^{\prime \prime}}{T_{\mathrm{w}}-T_{\mathrm{s}}}
$$

where the measured wall temperatures $\left(T_{\mathrm{w}}\right)$ were fitted to their axial position to reduce the uncertainty in the measurement.

The water temperature $\left(T_{\mathrm{f}}\right)$ was determined from the measured temperature change obtained from each thermopile and the inlet water temperature measurement. The water temperature gradient $\left(\mathrm{d} T_{\mathrm{f}} / \mathrm{d} z\right)$ was calculated with second-order finite difference equations using the measured water temperatures and their locations along the tube length, $z$. The water temperature gradients were then fitted with respect to the tube length typically to within $0.2 \mathrm{~K}$. Figure 4 shows an example plot of the water temperature measurements and the fit of the water temperature taken from Kedzierski and Kang (2018). The measured water temperatures are shown as open circles while the integrated fit of the water temperature gradient is represented by a solid line.

The fitted, local, axial water temperature gradient $\left(\mathrm{d} T_{\mathrm{f}} / \mathrm{d} z\right)$, the measured water mass flow rate $\left(\dot{m}_{\mathrm{f}}\right)$, and the properties of the water were used to calculate the local heat flux $\left(q^{\prime \prime}\right)$ to the micro-fin tube based on the actual inner surface area:

$$
q^{\prime \prime}=\frac{\dot{m}_{\mathrm{f}}}{p}\left(c_{\mathrm{p}_{\mathrm{f}}} \frac{\mathrm{d} T_{\mathrm{f}}}{\mathrm{d} z}+v_{\mathrm{f}} \frac{\mathrm{d} P_{\mathrm{f}}}{\mathrm{d} z}\right)
$$

where $p$ is the wetted perimeter of the inside of the micro-fin tube. The specific heat $\left(c_{\mathrm{pf}}\right)$ and the specific volume $\left(v_{f}\right)$ of the water were calculated locally as a function of the water temperature. The water pressure gradient $\left(\mathrm{d} P_{f} / \mathrm{d} z\right)$ was linearly interpolated between the pressure taps to the location of the wall thermocouples. The pressure gradient term was typically less than $3 \%$ of the temperature gradient term. The heat flux obtained by eq. (2) was reduced by the amount of heat lost to the surroundings. The heat loss to the surroundings was obtained by calibration of single phase heat transfer tests and it was based on the 
temperature difference between the room and the test fluid. Typically, the heat loss correction was less than $0.1 \%$ of that obtained from eq. (2). The magnitude of the relative uncertainty of the heat flux measurement was a function of heat flux, test fluid, and whether the refrigerant was in counterflow or parallel flow with respect to the water. Overall, the average uncertainty of the heat flux was roughly $15 \%$ and was approximately $7 \%$ and $20 \%$ of the measured value for counterflow and parallel flow, respectively.

Figure 5 shows example plots of the local heat flux as calculated from eq. (2) versus thermodynamic quality as taken from Kedzierski and Kang (2018) for R134a. Figure 5 shows both cases when the water and the refrigerant are in counterflow and parallel flow, respectively. The plot is for an all-liquid Reynolds number $(\mathrm{Re})$ of roughly 4418 and a refrigerant reduced pressure at the exit of the test section of approximately 0.09 . The transition from the first leg of the test section to the second leg causes a discontinuity in the heat flux profiles as a result of the adiabatic pressure drop in the bend. The pressure drop causes a decrease in refrigerant saturation that causes an increase in the difference between the water and the refrigerant temperature, which leads to an increase in the local heat flux. For the counterflow case, the heat flux increases from approximately $1 \mathrm{~kW} \cdot \mathrm{m}^{-2}$ at a quality near zero to approximately $14 \mathrm{~kW} \cdot \mathrm{m}^{-2}$ at a quality slightly greater than 0.7 . The parallel flow case has the opposite slope and a slightly different range of that for counterflow where the heat flux decreases from approximately $12 \mathrm{~kW} \cdot \mathrm{m}^{-2}$ at a quality near 0.05 to approximately $1 \mathrm{~kW} \cdot \mathrm{m}^{-2}$ at a quality of approximately 0.82 .

The thermodynamic and transport properties were calculated with version 10 of REFPROP (Lemmon et al., 2018) while using enthalpy and pressure as inputs. The enthalpy of the refrigerant liquid at the inlet of the test section was calculated from its measured temperature and pressure. The subsequent increase in refrigerant enthalpy along the test section was calculated from the local heat flux and the measured refrigerant mass flow rate. The refrigerant pressures were measured at six pressure taps along the test section. The pressure was linearly interpolated between the taps. The refrigerant exiting the test section was held to approximately $277.6 \mathrm{~K}$ while the fluid entering the test section was near zero quality for all of the tests. Considering that the tests were done for quality ranges between near zero and slightly greater than 0.7 , the saturation temperature of the test refrigerants decreased from roughly $282.0 \mathrm{~K}$ to $277.6 \mathrm{~K}$ for most tests due to the pressure drop. Because the temperature glide of R450A was less than $1 \mathrm{~K}$, as shown in Table 2, the variation in saturation temperature during tests was similar to that for the single-component refrigerants R1234yf and R134a.

The local Nusselt number $(\mathrm{Nu})$ was calculated using the hydraulic diameter and the heat transfer coefficient based on the actual inner surface area of the tube as:

$$
\mathrm{Nu}=\frac{h_{2 \phi} D_{h}}{k_{l}}
$$

The relative uncertainty of the $\mathrm{Nu}$ was between roughly $10 \%$ and $35 \%$. Measurements of $\mathrm{Nu}$ with uncertainties greater than $40 \%$ were discarded. The Nu uncertainty is given in the last column of the data tabulated in Kedzierski et al. (2021). The average uncertainty of $\mathrm{Nu}$ was approximately $20 \%$ as shown in Table 1. The reported uncertainties are for the individual measurements. Reduction in the uncertainty can be achieved with repeat measurements for the same operating conditions. However, repeat measurements are difficult to obtain due to the chaotic nature of two-phase flow and the many fixed parameters that need to be matched between measurements. 


\section{RESULTS}

The 8826 data points from the five NIST studies for R22, R32, R125, R134a, R1234yf, R1234ze(E), R407C, R410B, R448A, R449A, R450A, R452B, R513A, R515B, R32/R134a (27/73), and R32/R134a (30/70) are tabulated in Kedzierski et al. (2021), which contains the Nusselt and all-liquid Reynolds numbers and other reduced data that are typically used to characterize flow boiling. Kedzierski et al. (2021) contains the raw data measurements including the heat flux and the wall and water temperatures and locations. The column entitled "flow" provides a "C" or a "P" to indicate that the measurements were made for either counterflow or parallel flow between the refrigerant and water, respectively. All the parameters given in the online database are defined in the Nomenclature.

Table 3 shows the effect of using the most recent thermodynamic and transport properties from REFPROP (Lemmon et al., 2018) to reduce the NIST micro-fin boiling heat transfer measurements. Table 3 lists the tested refrigerants and the percent difference between the original published values for the $\mathrm{Nu}$ and the $\mathrm{Nu}$ as re-reduced with the current REFPROP (Lemmon et al., 2018). The largest average percent difference $(34.47 \%)$ occurred for R32/R134a (30/70), while the smallest percent difference $(0.15 \%)$ occurred for $\mathrm{R} 134 \mathrm{a}$. In general, mixed refrigerants exhibit larger percent differences because the fluid properties are more difficult to predict, which involves frequent refinement of the interaction parameters and property predictions. In contrast, R134a is the base-fluid that other refrigerant properties are predicted via the Extended Corresponding States (ECS). As a result, a significant effort was made early in REFPROP's development to well-establish the fluid properties for R134a. No deviations are shown for R513A and $\mathrm{R} 515 \mathrm{~B}$ because these were obtained from recent tests, which was reduced with the current properties.

The measured local convective boiling Nusselt numbers for the pure-refrigerants $\left(\mathrm{Nu}_{\mathrm{p}}\right)$ were correlated to:

$$
\mathrm{Nu}_{\mathrm{p}}=917.48 \mathrm{Re}^{\mathrm{C}_{1}} \operatorname{Pr}^{\mathrm{C}_{2}}\left(\frac{P_{\mathrm{s}}}{P_{\mathrm{c}}}\right)^{\mathrm{C}_{3}}\left(-\log _{10} \frac{P_{\mathrm{s}}}{P_{\mathrm{c}}}\right)^{\mathrm{C}_{4}} \mathrm{Bo}^{\mathrm{C}_{5}} \mathrm{Bd}^{\mathrm{C}_{6}} \mathrm{Co}^{\mathrm{C}_{7}}\left(\frac{\rho_{1}}{\rho_{\mathrm{v}}}\right)^{\mathrm{C}_{8}}\left(\frac{\mu_{1}}{\mu_{\mathrm{v}}}\right)^{\mathrm{C}_{9}}
$$

where

$$
\begin{aligned}
& C_{1}=0.40-0.19 x_{q} \\
& C_{2}=-4.06 x_{q}^{2} \\
& C_{3}=-26.30 x_{q}+50.72 x_{q}^{2} \\
& C_{4}=-22.31 x_{q}+43.70 x_{q}^{2} \\
& C_{5}=0.44-0.91 x_{q}+0.51 x_{q}^{2} \\
& C_{6}=0.38+1.80 x_{q} \\
& C_{7}=3.11 x_{q} \\
& C_{8}=-9.10 x_{q}+20.92 x_{q}^{2} \\
& C_{9}=-6.27 x_{q}+16.09 x_{q}^{2}
\end{aligned}
$$

Here, the all-liquid Reynolds number (Re), the Boiling number (Bo), the liquid Prandtl number (Pr), the 
reduced pressure $\left(P_{\mathrm{s}} / P_{\mathrm{c}}\right)$, the Bond number $(\mathrm{Bd})$, the convection number $(\mathrm{Co})$, and the quality $\left(x_{\mathrm{q}}\right)$ are all evaluated locally at the saturation temperature. The all-liquid Reynolds number and the Nusselt number are based on the hydraulic diameter $\left(D_{\mathrm{h}}\right)$. The Nusselt number is also based on the actual inner surface area of the tube $\left(A_{\mathrm{i}}\right)$. The absolute percent difference between the measured $\mathrm{Nu}_{\mathrm{p}}$ and those predicted by eq. (4) was on average $6.8 \%$. As shown in Fig. 6,97\% of the measurements are predicted to within $\pm 20 \%$. In addition, the predictions are well centered about the mean because the average percent difference between the measured and predicted $\mathrm{Nu}$ was approximately $1.5 \%$.

In order to predict the flow boiling Nusselt Number for mixtures ( $\mathrm{Num}$ ), a correction factor for eq. (4) was developed. This was done by multiplying the single-component Nusselt Number $\left(\mathrm{Nu}_{\mathrm{p}}\right)$ by a modifier to predict multi-component mixtures:

$$
\mathrm{Nu}_{\mathrm{m}}=\mathrm{Nu}_{\mathrm{p}}\left(1-0.049 \mathrm{Bo}^{\mathrm{C}_{10}}\left(\frac{T_{\mathrm{d}}-T_{\mathrm{b}}}{T_{\mathrm{b}}}\right)^{\mathrm{C}_{11}}\right)
$$

where

$$
\begin{aligned}
& C_{10}=-0.82 x_{q}+1.17 x_{q}^{2} \\
& C_{11}=-0.18+1.13 x_{q}-1.55 x_{q}^{2}
\end{aligned}
$$

where $\mathrm{Nu}_{\mathrm{p}}$ is calculated using eq. (4) and $T_{\mathrm{d}}$ and $T_{\mathrm{b}}$ are the dew-point and bubble-point temperatures, respectively, evaluated at the local saturation pressure and overall composition of the mixture. The $T_{\mathrm{d}}-T_{\mathrm{b}}$ difference is commonly called the temperature glide of the mixture. The temperature glide represents the potential for a heat transfer degradation due to mass transfer resistance and loss of available superheat as caused by concentration gradients (Kedzierski et al., 1992). Consequently, the terms in eq. (5) that modify $\mathrm{Nu}_{p}$ describe the mixture degradation effect, which is a function of the normalized temperature glide, and the boiling number. A single-component refrigerant would have zero temperature glide, which would result in the mixture degradation effect, represented by the bracketed term, being equal to one. The absolute percent difference between the measured $\mathrm{Nu}_{\mathrm{p}}$ and those predicted by eq. (4) was on average $12.3 \%$. Figure 7 shows that roughly $81 \%$ of the measurements are predicted to within $\pm 20 \%$. In addition, the predictions are fairly well centered about the mean because the average precent difference between the measured and predicted $\mathrm{Nu}$ was approximately $6.6 \%$.

As determined by using the flow map of Yu et al. (2002) for micro-fin tubes, approximately $70 \%$ of the measurements were in annular or semi-annular flow with the remaining flow being in low quality intermittent flow. This is not surprising considering that Manwell and Bergles (1990) suggest that annularlike flow is strongly encouraged in micro-fin tubes because of the fins that rifle along the tube axis that induce wetting of the upper tube wall. Recently, Lin et al. (2021) have shown that nearly all the micro-fin tube flow boiling data available in the literature can be fit by two correlations depending on a dimensionless parameter that roughly corresponds to correlations for low and high quality. In a similar way, it is believed that the present correlation captures the effect of flow pattern by being continuously variable with respect to quality via the exponents, which are functions of quality.

Figures 8 through 13 provide representative plots of the Nu versus thermodynamic quality $\left(x_{q}\right)$. The figures compare the boiling Nusselt numbers predicted with eq. (4) for the micro-fin tube to those measured 
for the single component refrigerants: R22, R32, R125, R134a, R1234yf and R1234ze(E). The dashed lines are multi-use $95 \%$ confidence intervals on the measured $\mathrm{Nu}$. The open circles show the measured $\mathrm{Nu}$. The solid lines are predictions, which were obtained from eq. (4). In a similar manner to Figs. 8 through 13, Figs. 14 through 22 provide a comparison between the measured $\mathrm{Nu}$ for the refrigerant mixtures to the Nu predicted with eq. (5). Figures 14 through 22 illustrate the refrigerants R407C, R410B, R448A, R449A, R450A, R452B, R513A, R515B, and R32/R134a (27/73), respectively.

\section{CONCLUSIONS}

Local convective boiling heat transfer measurements for a micro-fin tube for mixed and single component refrigerants from five NIST studies are presented here. Previously published measurements were reanalyzed here with current fluid properties for R22, R32, R125, R134a, R513A, R1234yf, R1234ze(E), R407C, R410B, R448A, R449A, R450A, R452B, R513A, R515B, R32/R134a (27/73), and R32/R134a $(30 / 70)$.

The re-evaluation of the measured Nusselt numbers resulted in as large as a $40 \%$ correction for mixed refrigerants and no correction for recently published measurements. A new correlation for convective boiling Nusselt numbers for all the test refrigerants was developed that predicted the measurements to within $\pm 6.8 \%$ for single components and $12.3 \%$ for mixtures. A website with the corrected measurements was established and is available for download.

In general, the measured boiling heat-transfer coefficient increased with increasing qualities when the local heat flux increased with respect to quality. In contrast, for decreasing heat flux with respect to increasing quality, the measured heat transfer coefficient was relatively constant. Mixed refrigerants were predicted with the aid of the boiling number and the dimensionless temperature glide.

\section{ACKNOWLEDGEMENTS}

This work was funded by NIST. The authors thank the following for their constructive criticism of the first draft of the manuscript: W. Vance Payne from NIST, and Ki-Jung Park from the Korea Atomic Energy Research Institute. Thanks also go to Wolverine Tube, Inc., for supplying the Turbo-A, micro-fin tube for the test section, and to Chemours and Honeywell for supplying the test refrigerants. 


\section{NOMENCLATURE}

\section{English symbols}

$A_{\mathrm{c}} \quad$ cross-sectional area $\left(\mathrm{m}^{2}\right)$

Bd Bond number, $\frac{g D_{\mathrm{h}}\left(\rho_{1}-\rho_{\mathrm{v}}\right) e}{\sigma n_{\mathrm{f}}}$

Bo local boiling number, $\frac{q^{\prime \prime}}{G_{r} i_{f g}}$

Co convection number, $\left(\frac{1-x_{\mathrm{q}}}{x_{\mathrm{q}}}\right)^{0.8}\left(\frac{\rho_{\mathrm{v}}}{\rho_{1}}\right)^{0.5}$

$c_{\mathrm{p}} \quad$ specific heat $\left(\mathrm{J} \mathrm{kg}^{-1} \mathrm{~K}^{-1}\right)$

$C \quad$ coefficients given in eq. (5)

$D_{\mathrm{e}} \quad$ equivalent inner diameter of smooth tube, $\sqrt{\frac{4 A_{\mathrm{c}}}{\pi}}(\mathrm{m})$

$D_{\mathrm{h}} \quad$ hydraulic diameter of micro-fin tube (m)

$e \quad$ fin height (mm)

$f \quad$ Fanning friction factor

$g \quad$ acceleration due to gravity $\left(\mathrm{m} \mathrm{s}^{-2}\right)$

$G \quad$ total mass velocity $\left(\mathrm{kg} \mathrm{m}^{-2} \mathrm{~s}^{-1}\right)$

$h_{2 \phi} \quad$ local two-phase heat-transfer coefficient $\left(\mathrm{W} \mathrm{m}^{-2} \cdot \mathrm{K}^{-1}\right)$

$i_{\mathrm{fg}} \quad$ latent heat of vaporization $\left(\mathrm{J} \mathrm{kg}^{-1}\right)$

$k$ refrigerant thermal conductivity $\left(\mathrm{W} \mathrm{m}^{-1} \mathrm{~K}^{-1}\right)$

$\mathrm{n}_{\mathrm{f}} \quad$ number of micro-fins (-)

$\mathrm{Nu} \quad$ local Nusselt number based on $D_{\mathrm{h}}$

$\dot{m} \quad$ mass flow rate $\left(\mathrm{kg} \mathrm{s}^{-1}\right)$

$M_{\mathrm{w}} \quad$ molar mass $\left(\mathrm{g} \mathrm{mole}^{-1}\right)$

$p \quad$ wetted perimeter $(\mathrm{m})$

$P \quad$ local fluid pressure $(\mathrm{Pa})$

$\operatorname{Pr} \quad$ liquid refrigerant Prandtl number $\left.\frac{c_{p} \mu}{k}\right|_{r, l}$

$q^{\prime \prime} \quad$ local heat flux based on $A_{\mathrm{i}}\left(\mathrm{W} \mathrm{m}^{-2}\right)$

$\operatorname{Re} \quad$ all liquid, refrigerant Reynolds number based on $D \mathrm{~h}, \operatorname{Re}=\frac{G_{r} D_{h}}{\mu_{r, l}}$

$s \quad$ distance between fins ( $\mathrm{mm})$

$T$ temperature $(\mathrm{K})$

$t_{b} \quad$ bottom thickness of fin (mm)

$t_{w} \quad$ tube wall thickness (mm)

$U$ expanded relative uncertainty (\%)

$x_{\mathrm{q}} \quad$ thermodynamic mass quality (-)

$z \quad$ axial distance $(\mathrm{m})$ 


\section{Greek symbols}

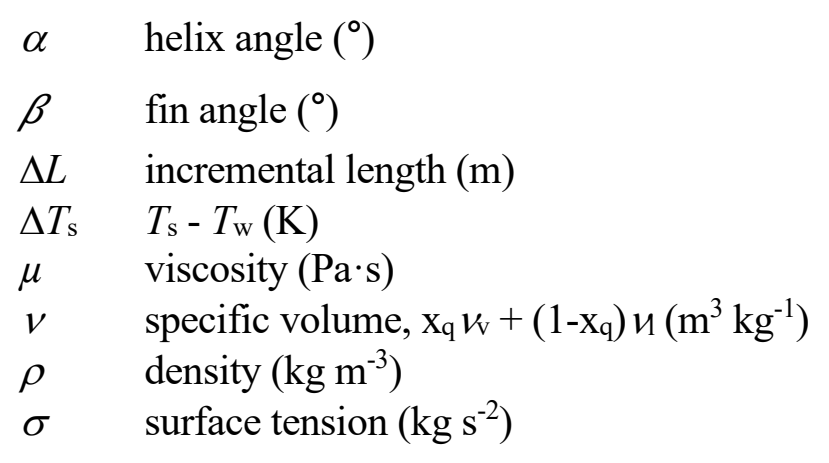

\section{Subscripts}

b bubble point

c critical condition

d dew point

f water

i inside, inlet

1 liquid

o outlet, exit

$\mathrm{p}$ prediction, single component

$r \quad$ refrigerant

s saturated state

V vapor

w heat transfer surface 


\section{REFERENCES}

Bailey, E. G. 1942. Liquid Vaporizing Tube, US patent 2,279,548.

https://patents.google.com/patent/US2279548A/en

Bogart, J. 2021. Private Communications. York International, York, PA.

Directive 2006/40/EC of The European Parliament \& of the Council of 17 May 2006 Relating to Emissions from Air-Conditioning Systems in Motor Vehicles \& Amending Council Directive 70/156/EC. Official Journal of the European Union, 49(L 161):12-18.

https://www.legislation.gov.uk/eudr/2006/40/adopted/data.pdf

Domanski, P.A., McLinden, M.O., Valeri I. Babushok, V.I., Bell, I.H., Fortin, T.J., Hegetschweiler, M.J., Kedzierski, M.A., Kim, D.K., Lin, L., Linteris, G.T., Outcalt, S.L., Perkins, R.A., Rowane, A. Skye, H.M. 2021. Low-GWP Alternative Refrigerant Blends for HFC-134a: Interim Report, NISTIR $\underline{8395}$, U.S. Department of Commerce, Washington, D.C. https://doi.org/10.6028/NIST.IR.8395

Hamilton, L. J., Kedzierski, M. A, and Kaul, M. P. 2008. Horizontal convective boiling of pure and mixed refrigerants within a micro-fin tube. Journal of Enhanced Heat Transfer 15(3):211-226. https://doi.org/10.1615/JEnhHeatTransf.v15.i3.30

Kedzierski, M. A., Lin, L., Kang, D. Y., Park, K. J., Hamilton, L. J., and Kaul, M. P. 2021. Legacy NIST Horizontal Micro-Fin Tube Convective Boiling Measurements, https://doi.org/10.18434/mds22498 (Accessed 2021-11-2)

Kedzierski, M. A., Kang, D, 2018 Horizontal Convective Boiling of R1234yf, R134a, and R450A within a Micro-Fin Tube, International Journal of Refrigeration, doi:10.1016/j.ijrefrig.2018.02.021

Kedzierski, M. A., and Kang, D. Y. 2016. Horizontal convective boiling of R448A, R449A, and R452B within a micro-fin tube, Science and Technology for the Built Environment 22:8, 1090-1103.

Kedzierski, M. A., and Park, K. J. 2013. Horizontal convective boiling of R134a, R1234yf/R134a, and R1234ze(E) within a micro-fin tube. J. of Enhanced Heat Transfer. 20(4): 333-346.

Kedzierski, M. A., Kim, J. H., and Didion, D. A. 1992. Causes of the apparent heat transfer degradation for refrigerant mixtures. Two-Phase Flow and Heat Transfer, HTD-Vol. 197, J. H. Kim, R. A. Nelson, and A. Hashemi, Eds., ASME, New York, 197:149-158.

Kyoto Protocol 1997. United Nations Framework Convention on Climate Change. United Nations (UN), New York, NY, USA.

Lemmon, E. W., Huber, M. L., and McLinden, M. O. 2018. NIST Standard Reference Database 23 (REFPROP), Version 10. Private Communications with McLinden, National Institute of Standards and Technology, Boulder, CO. 
Lin, L., Gao, L., Kedzierski, M. A., and Hwang, Y. 2021. A general model for flow boiling heat transfer in microfin tubes based on a new neural network architecture, submitted to International Journal of $\underline{\text { Heat and Mass Transfer }}$

Manwell, S.P., and Bergles, A.E. 1990. Gas-liquid flow patterns in refrigerant-oil mixtures. $A S H R A E$ Transactions 96(2):456-464.

Montreal Protocol 1987. Montreal Protocol on Substances that Deplete the Ozone Layer. United Nations (UN), New York, NY, USA (1987 with subsequent amendments).

Webb, R. L., and Kim, N-H. 2005. Principles of Enhanced Heat Transfer, $2^{\text {nd }}$ ed., Taylor \& Francis, New York.

Yu, M., Lin, T., and Tseng, C. 2002 Heat transfer and flow pattern during two-phase flow boiling of R134a in horizontal smooth and micro-fin tubes. International Journal of Refrigeration 25(6):789-798. 


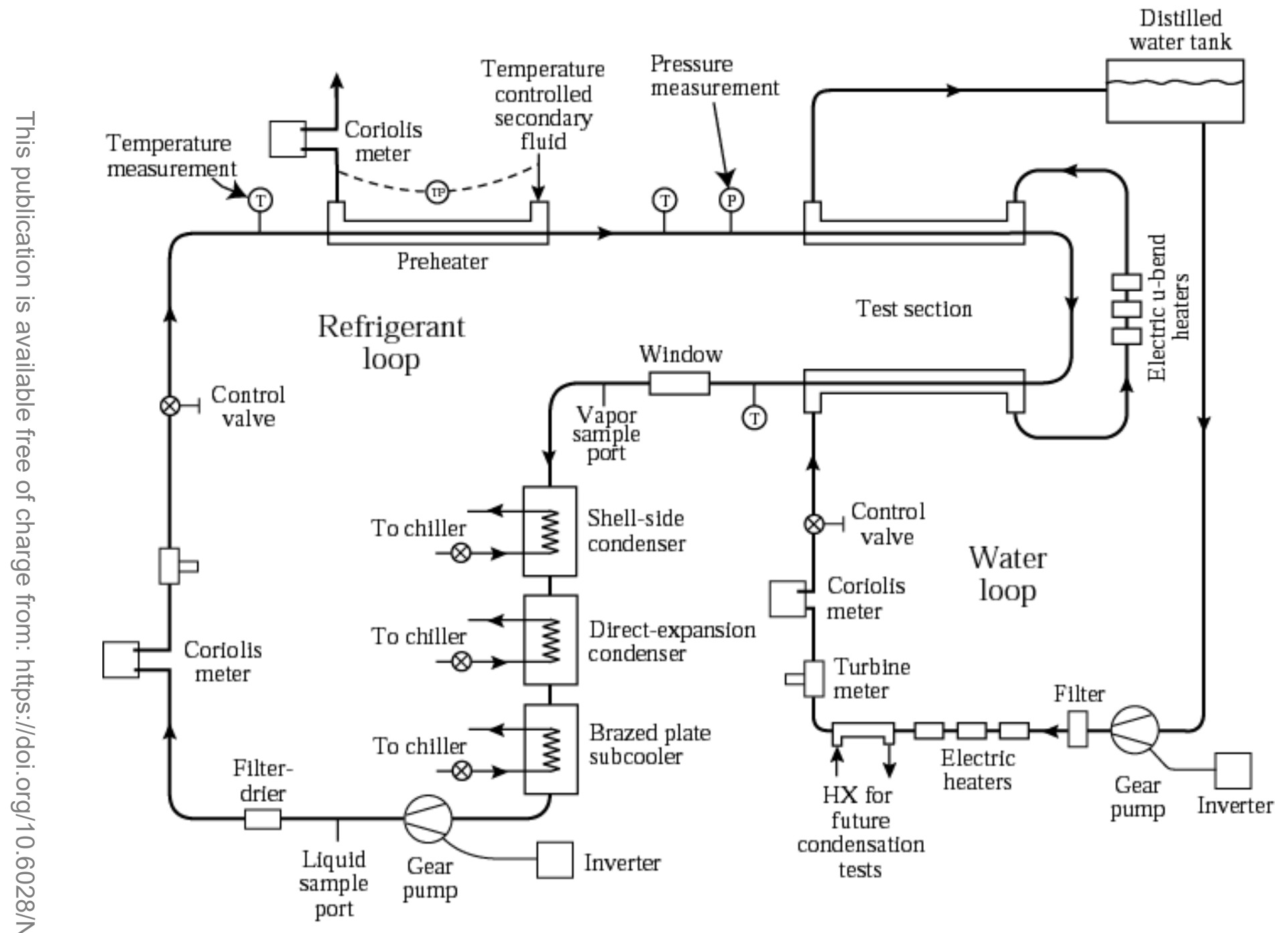

Figure 1 Schematic of test rig showing counterflow arrangement 


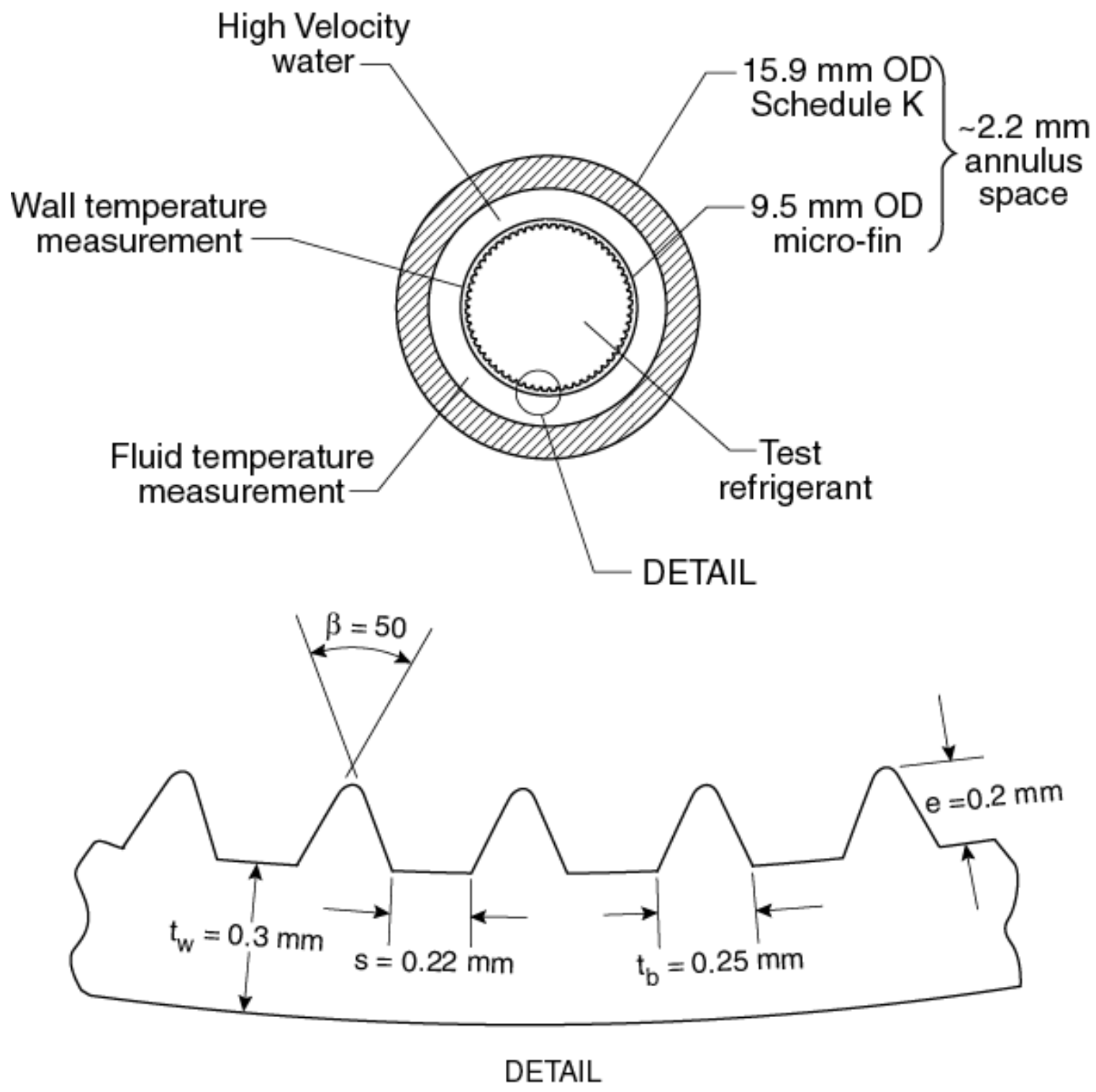

Figure 2 Test section cross section 


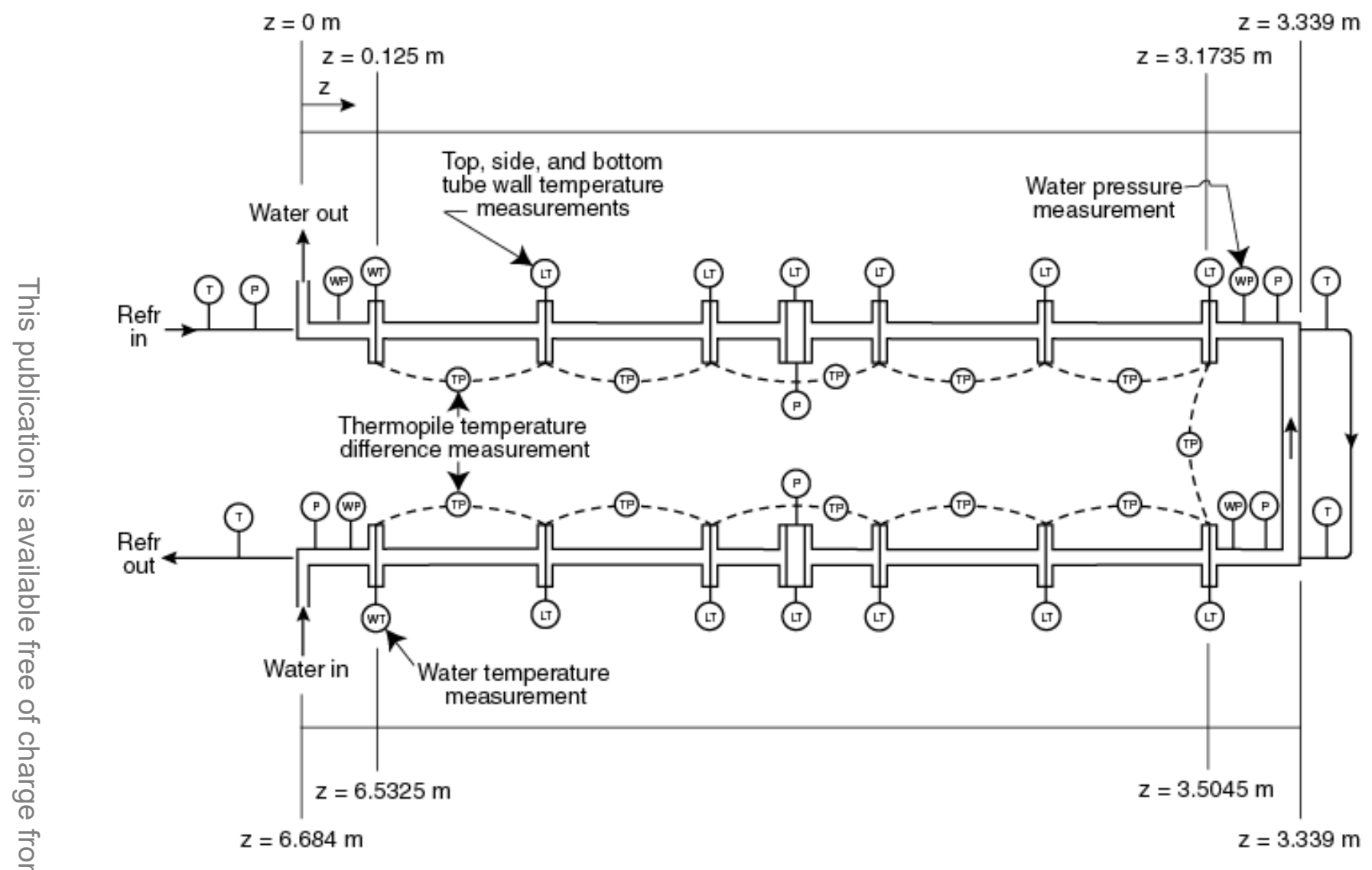

Figure 3 Detailed schematic of test section (counterflow) 


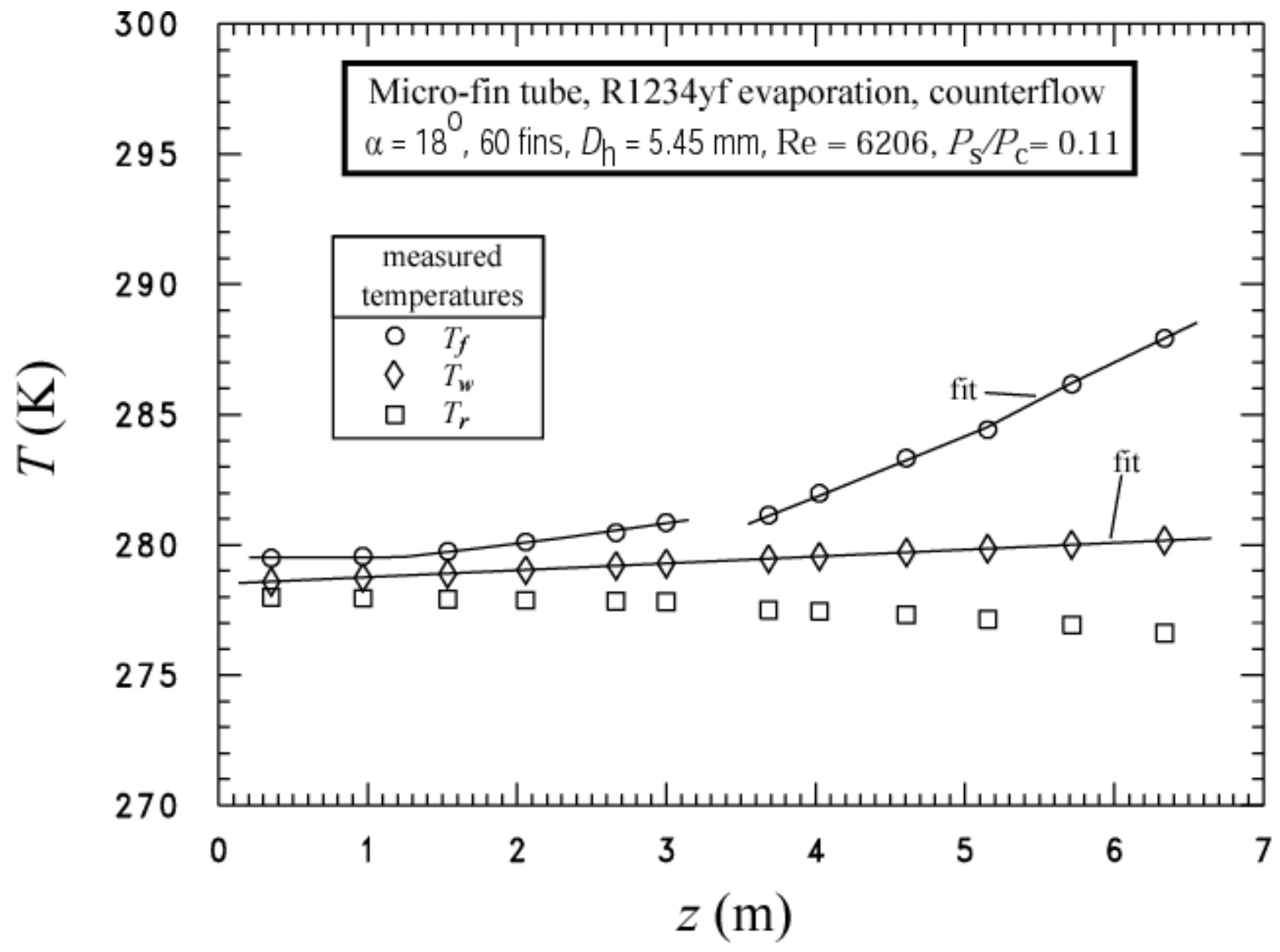

Figure 4 Counterflow temperature profiles for a R1234yf test 


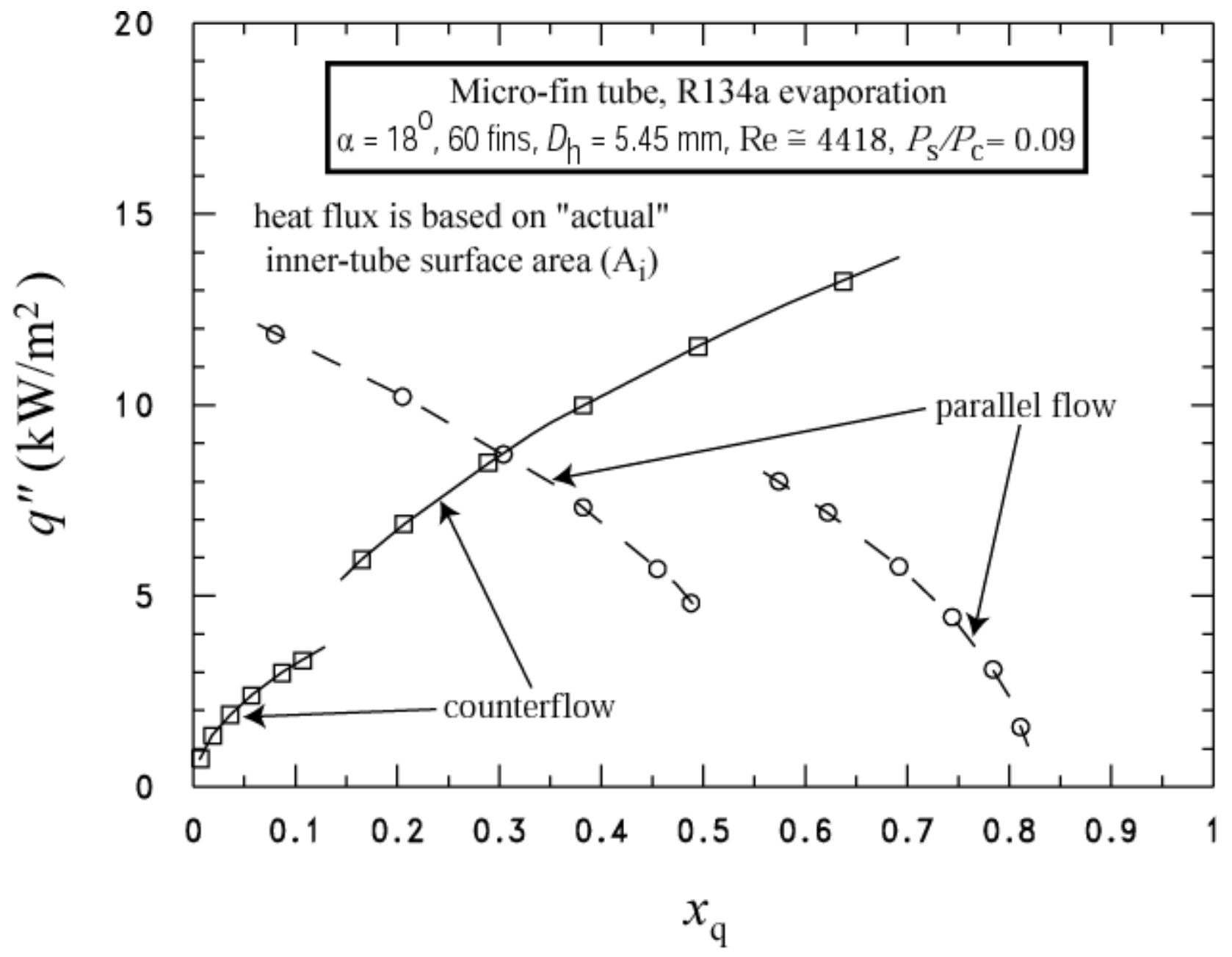

Figure 5 Heat flux distribution for R134a 


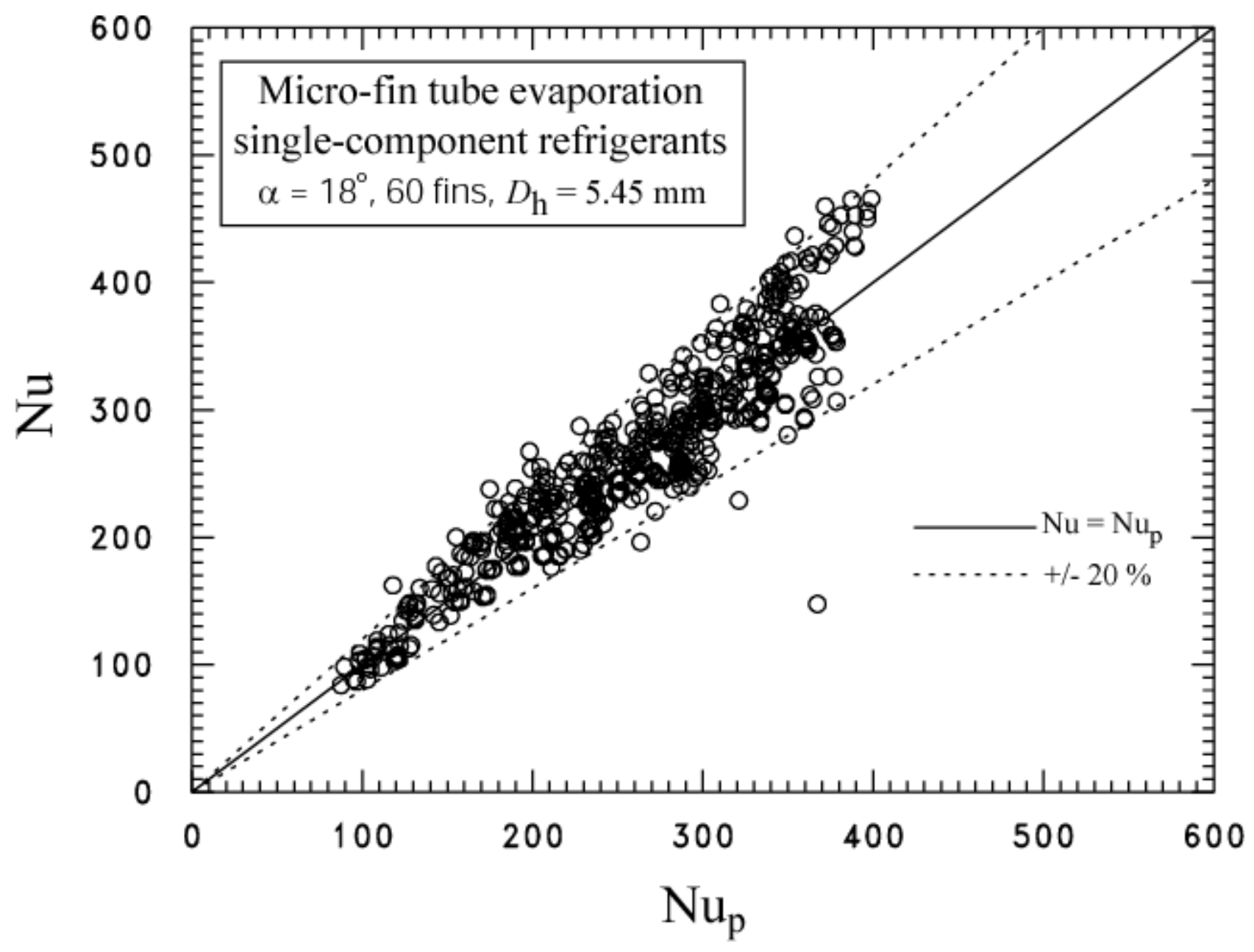

Figure 6 Comparison between measured Nusselt numbers and those predicted by eq. (4) 


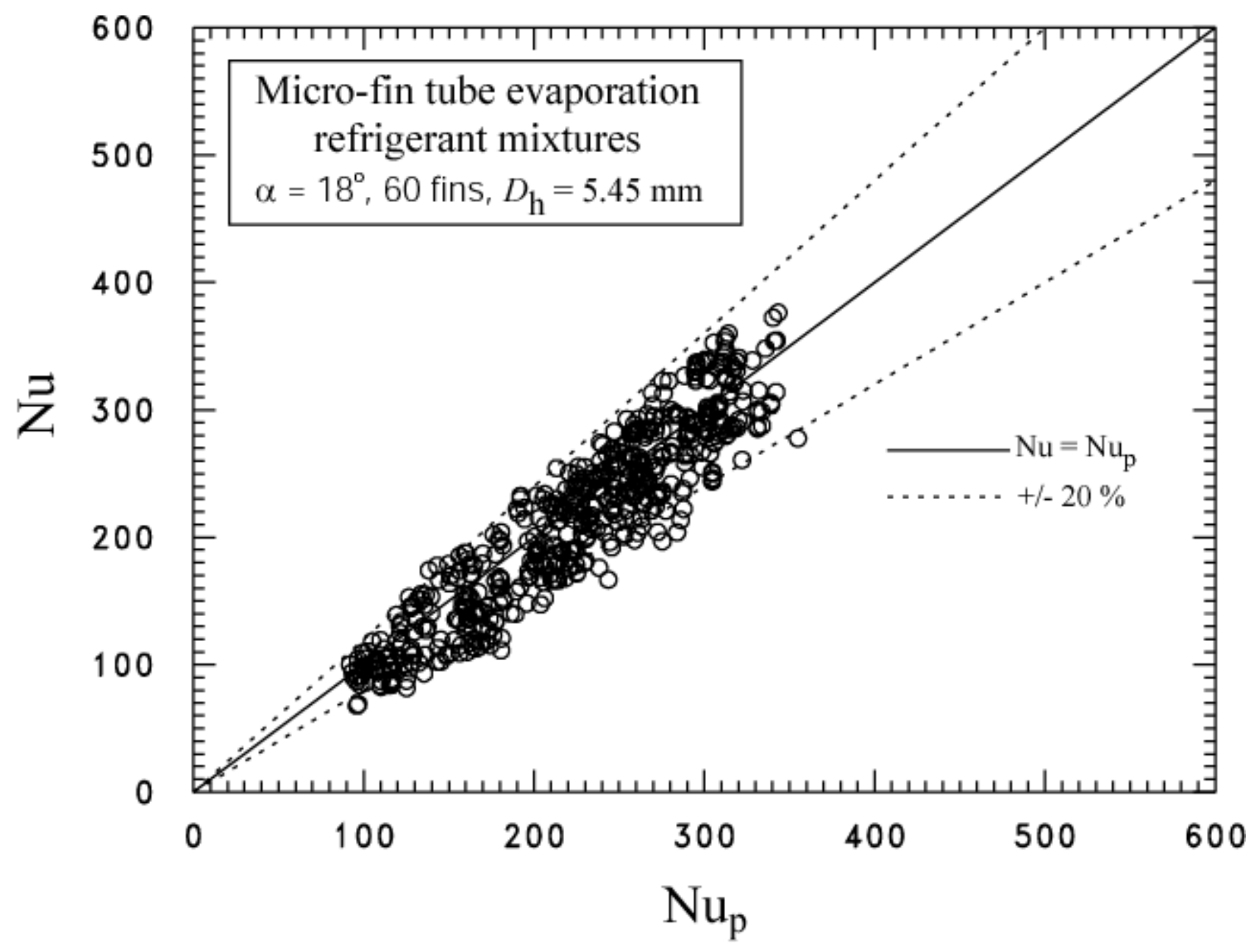

Figure 7 Comparison between measured Nusselt numbers and those predicted by eq. (5) 


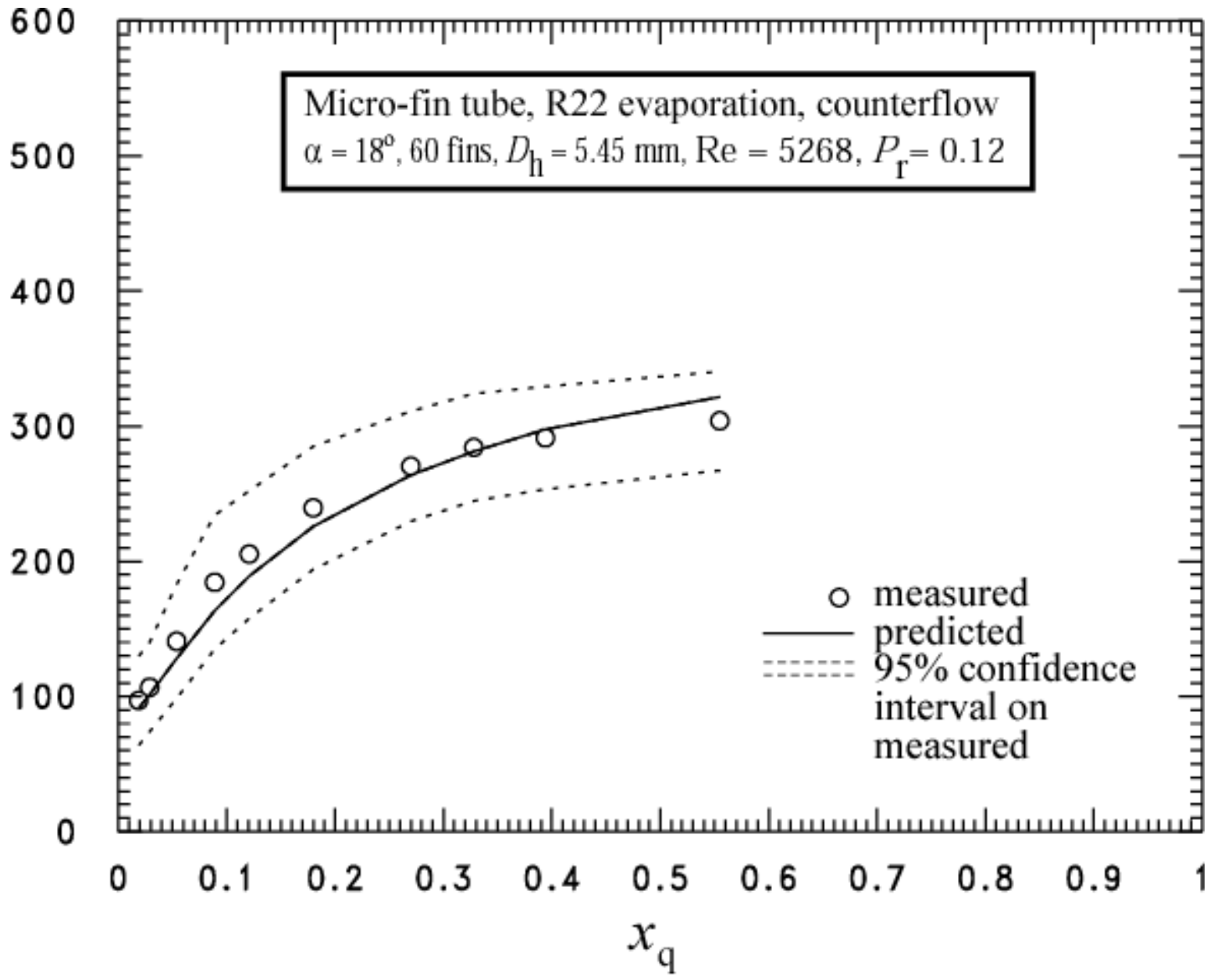

Figure 8 Comparison between measured Nusselt numbers and those predicted by eq. (4) for R22 


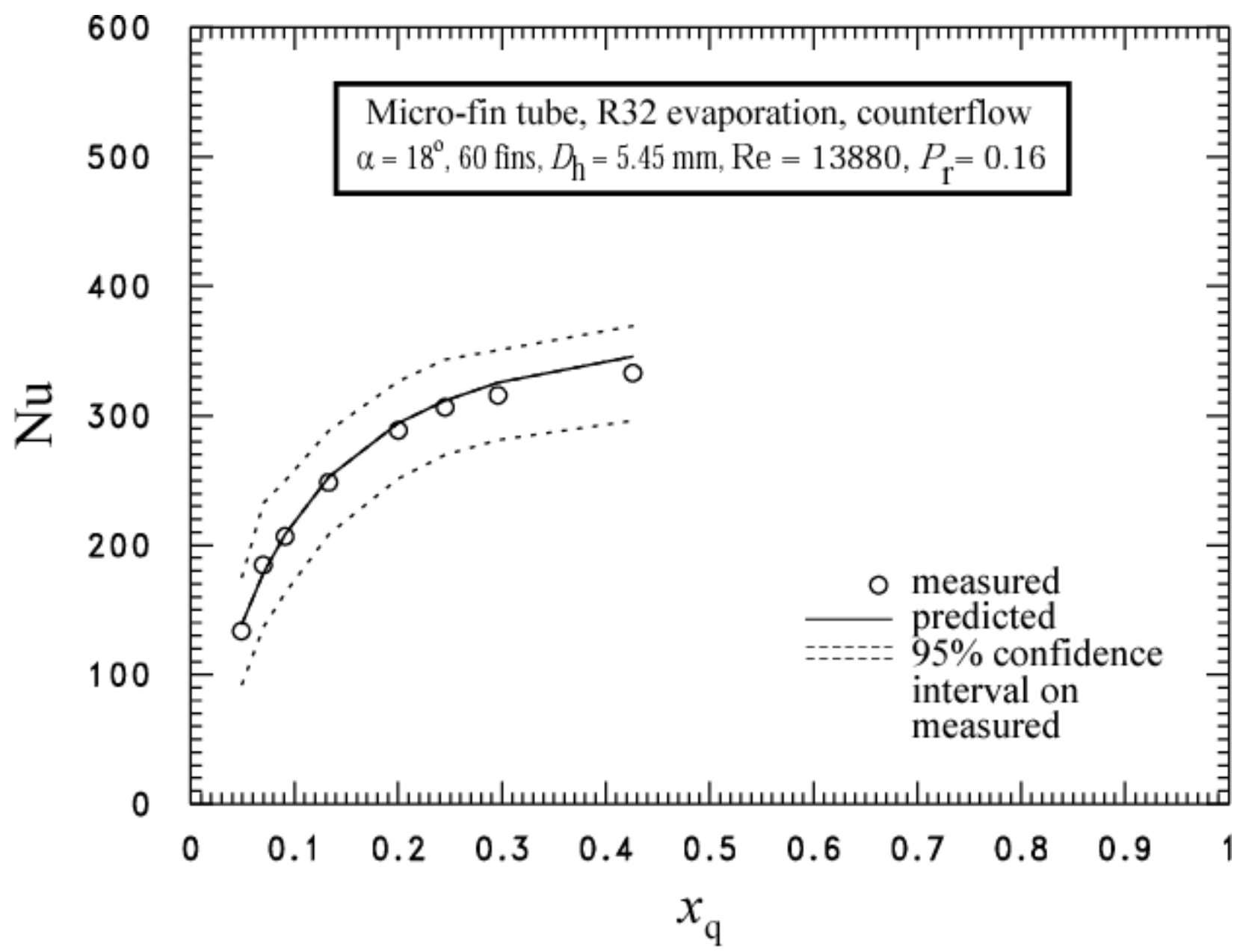

Figure 9 Comparison between measured Nusselt numbers and those predicted by eq. (4) for R32 


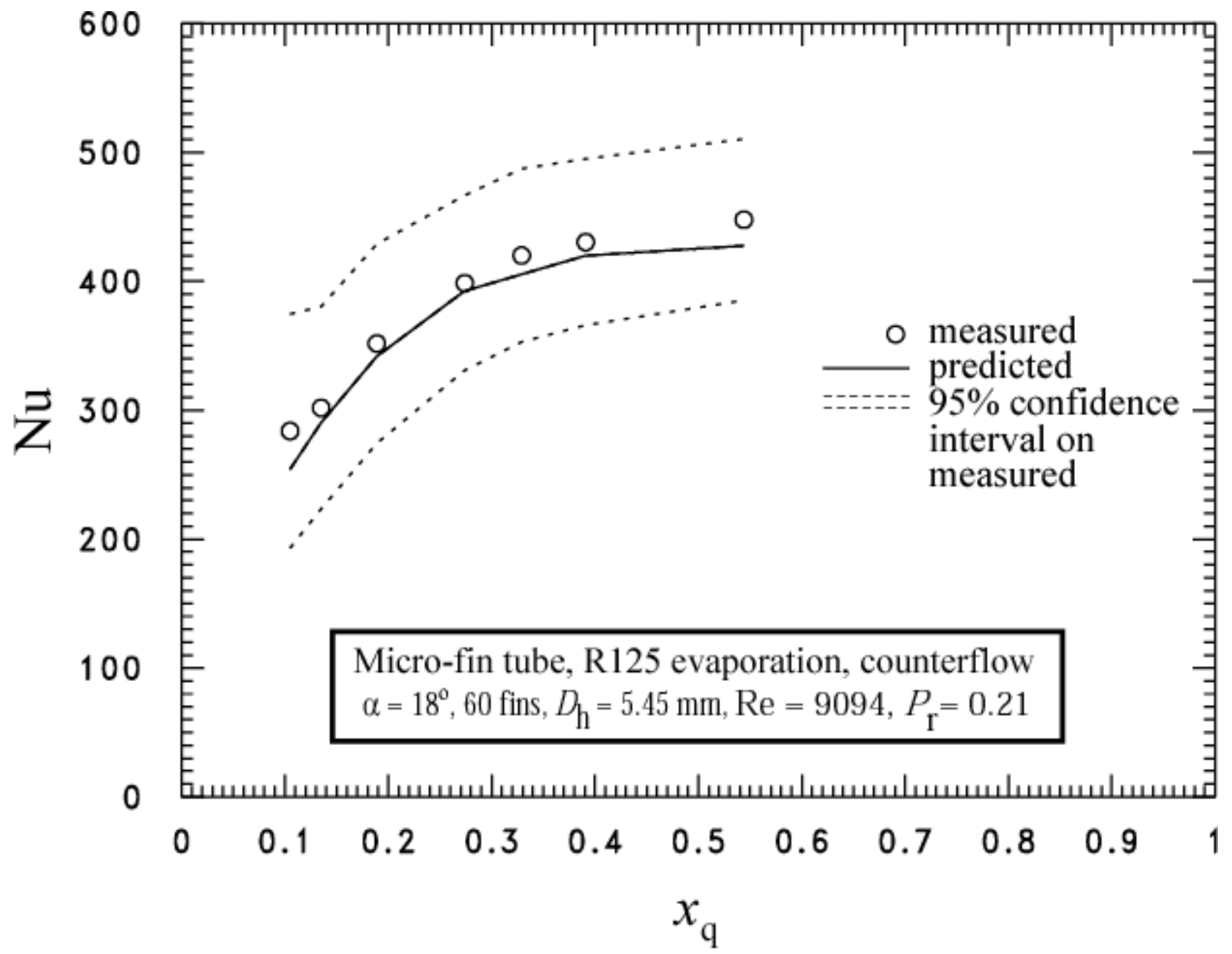

Figure 10 Comparison between measured Nusselt numbers and those predicted by eq. (4) for R125 


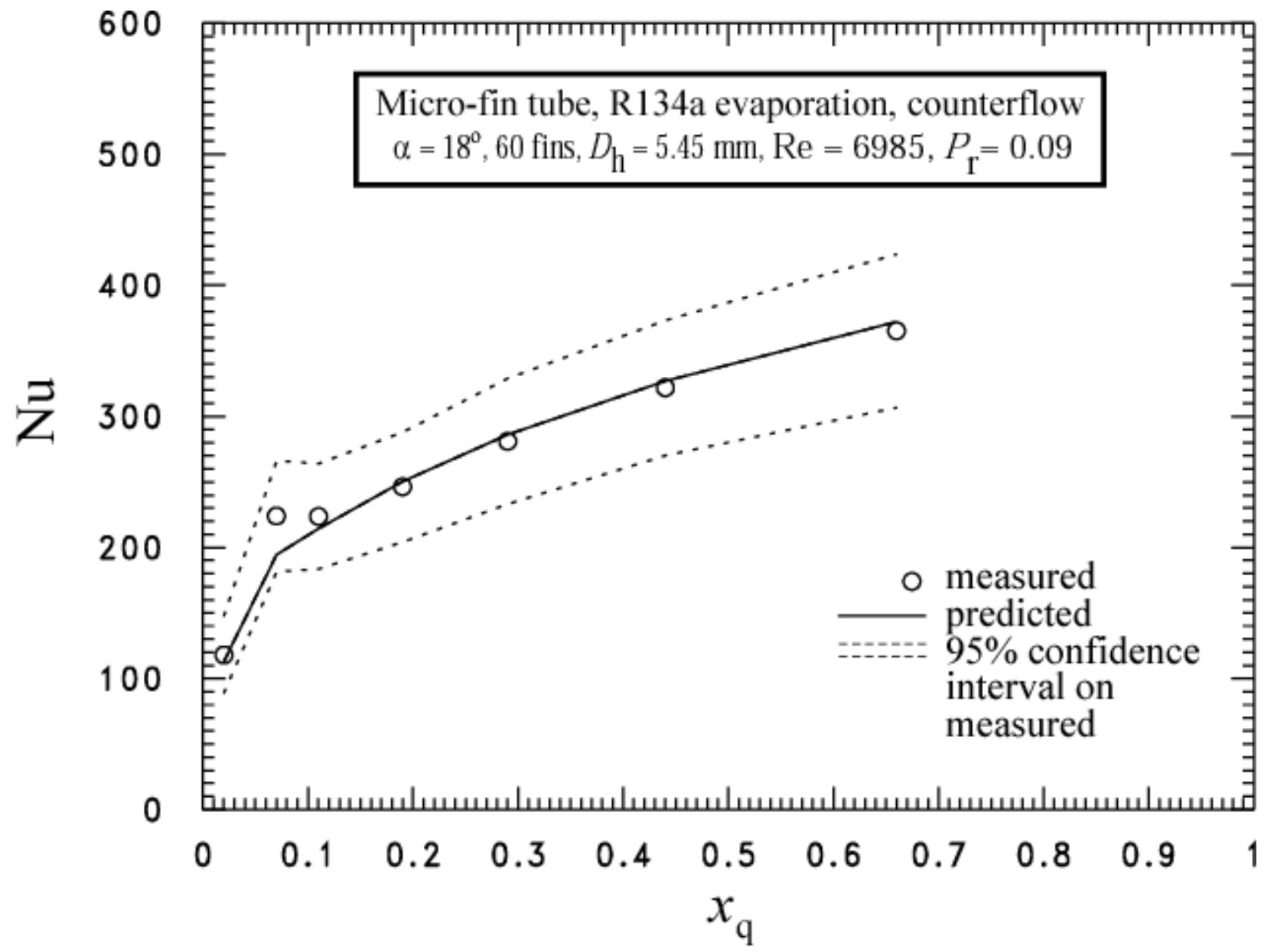

Figure 11 Comparison between measured Nusselt numbers and those predicted by eq. (4) for R134a 


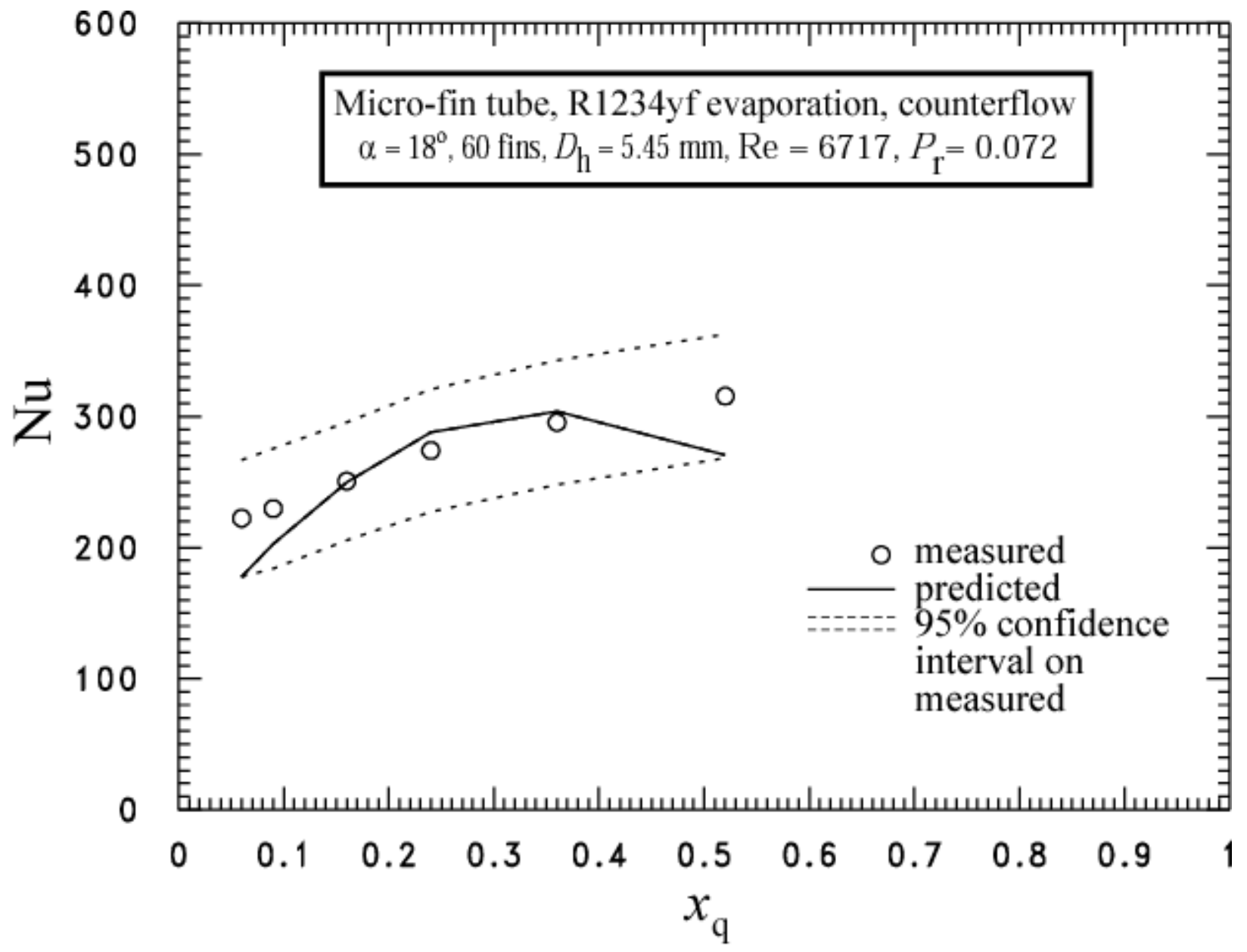

Figure 12 Comparison between measured Nusselt numbers and those predicted by eq. (4) for R1234yf 


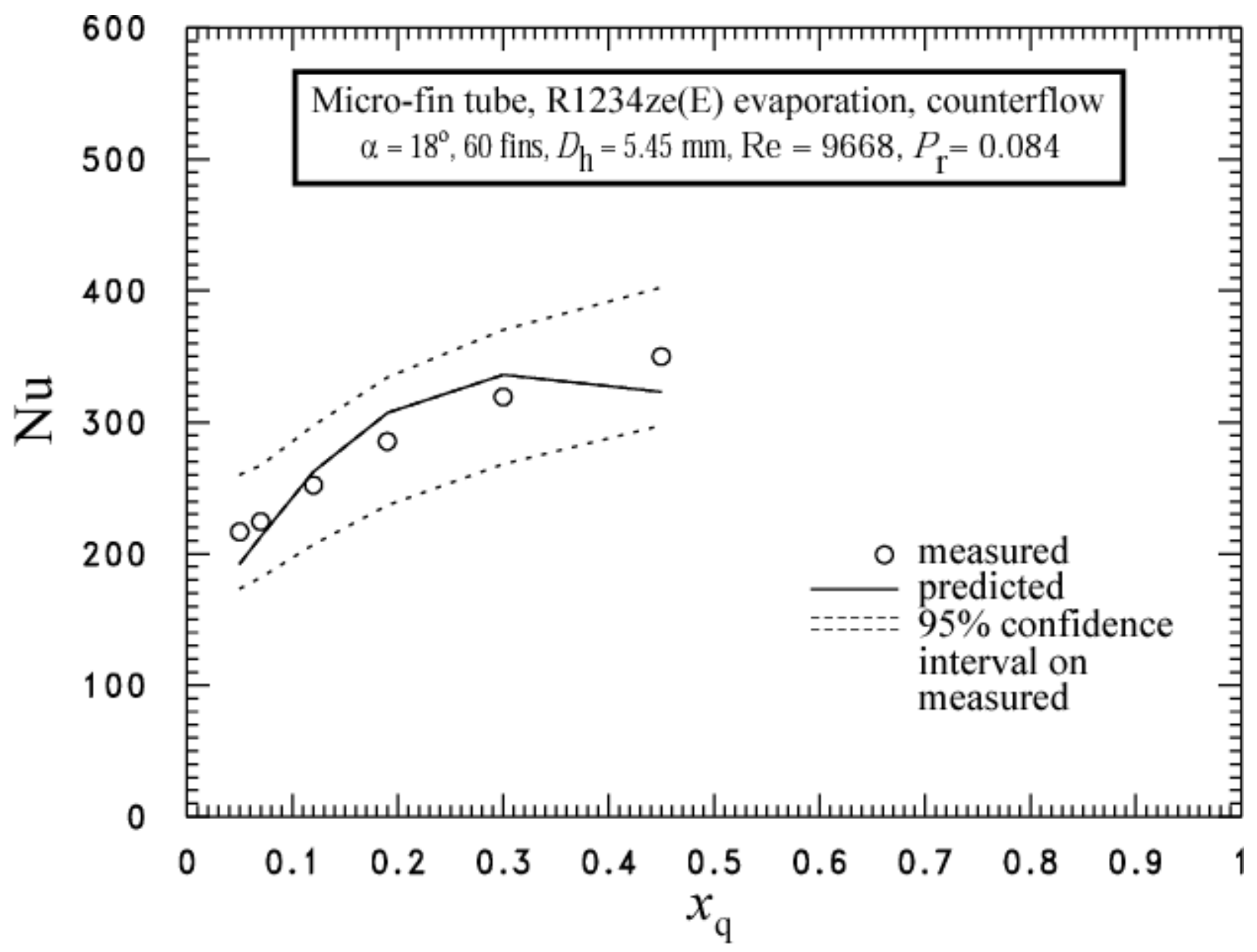

Figure 13 Comparison between measured Nusselt numbers and those predicted by eq. (4) for R1234ze(E) 


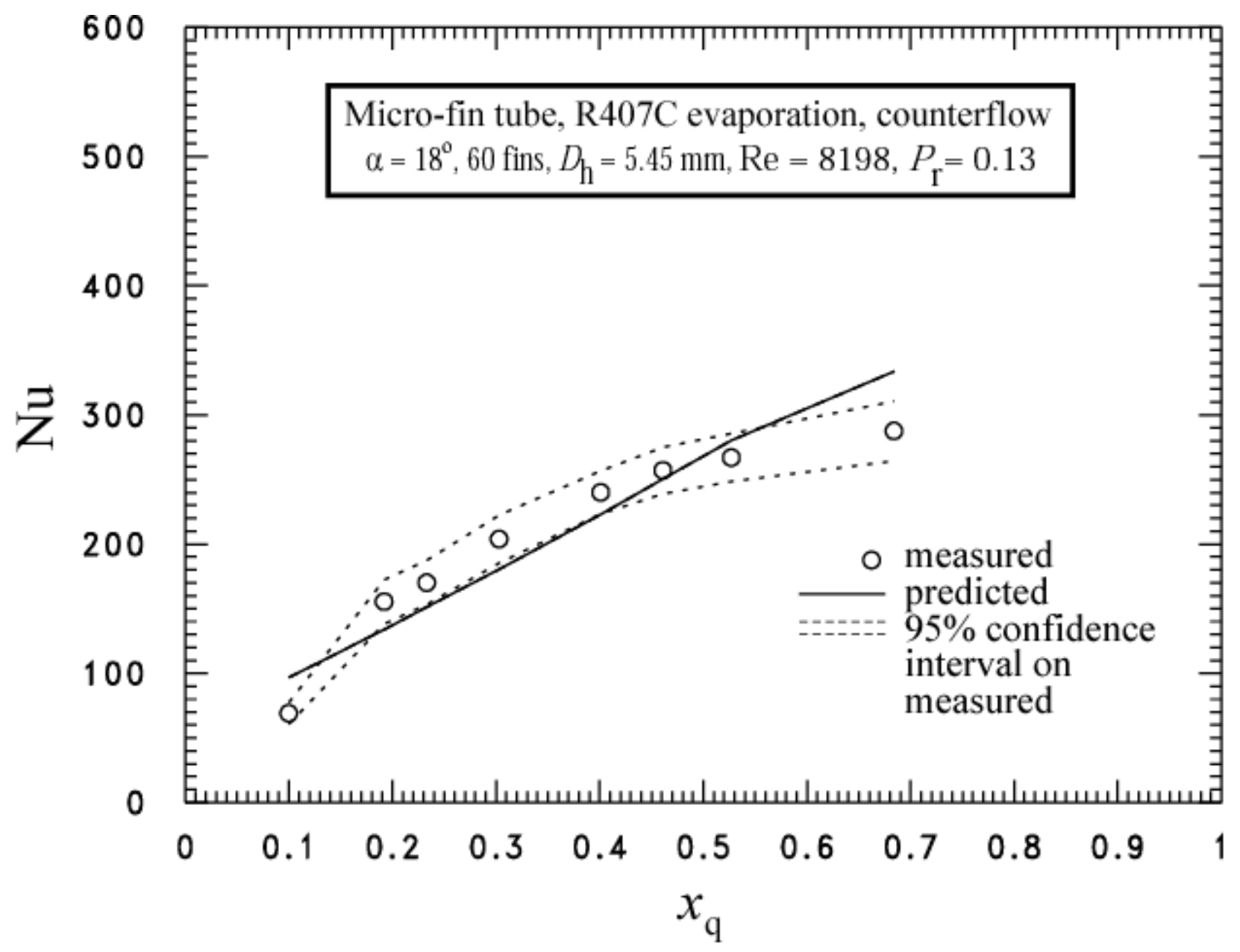

Figure 14 Comparison between measured Nusselt numbers and those predicted by eq. (5) for R407C 


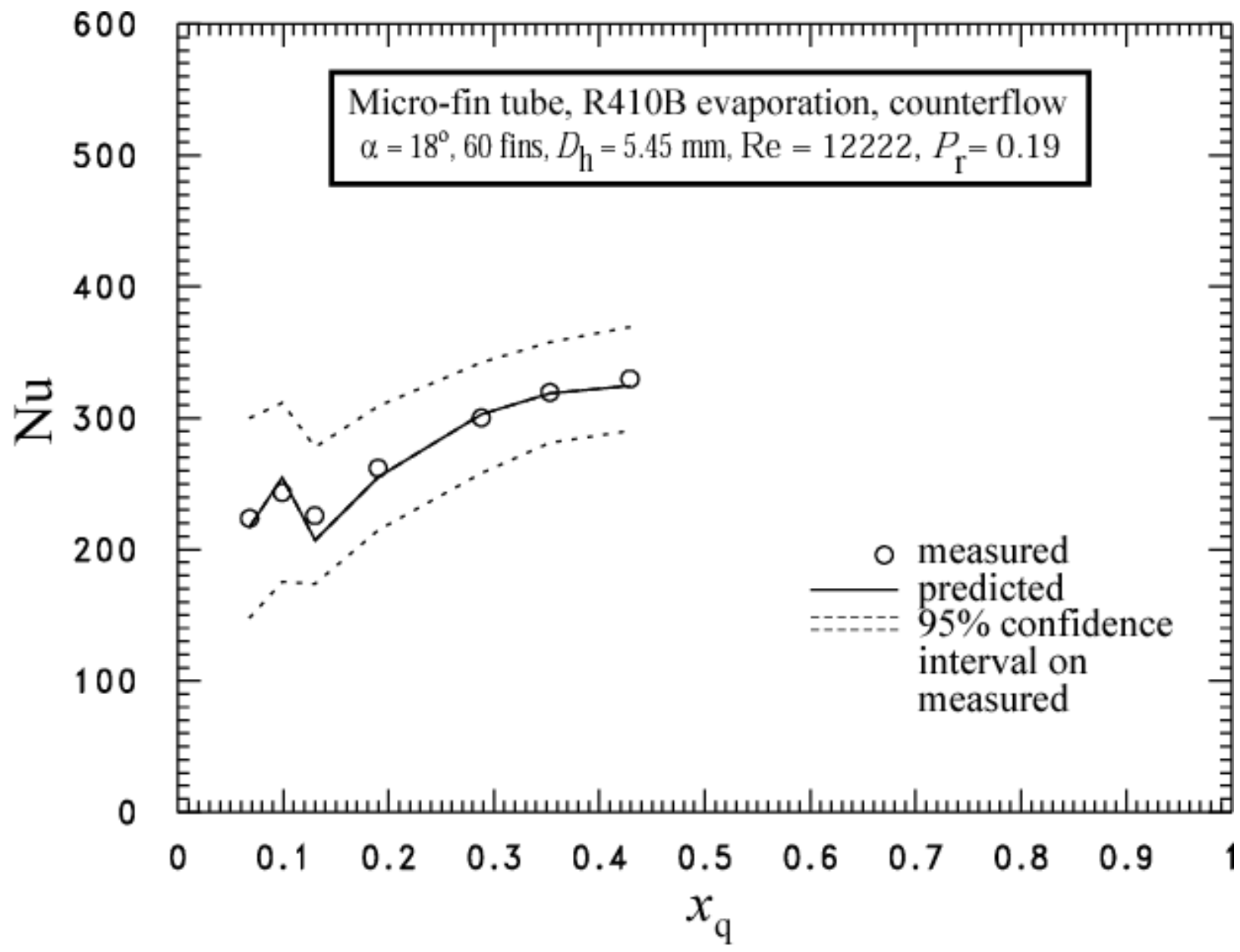

Figure 15 Comparison between measured Nusselt numbers and those predicted by eq. (5) for R410B 


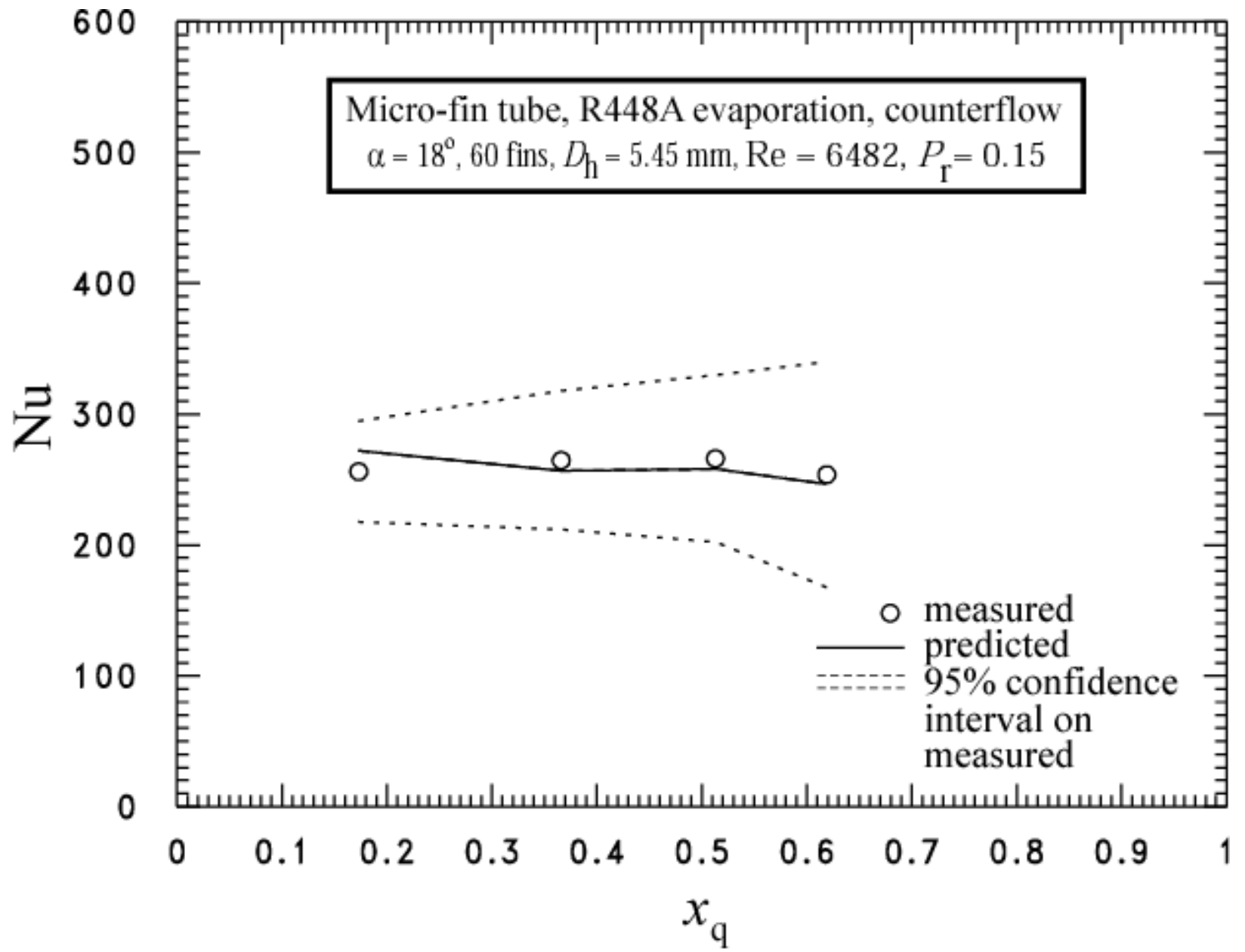

Figure 16 Comparison between measured Nusselt numbers and those predicted by eq. (5) for R448A 


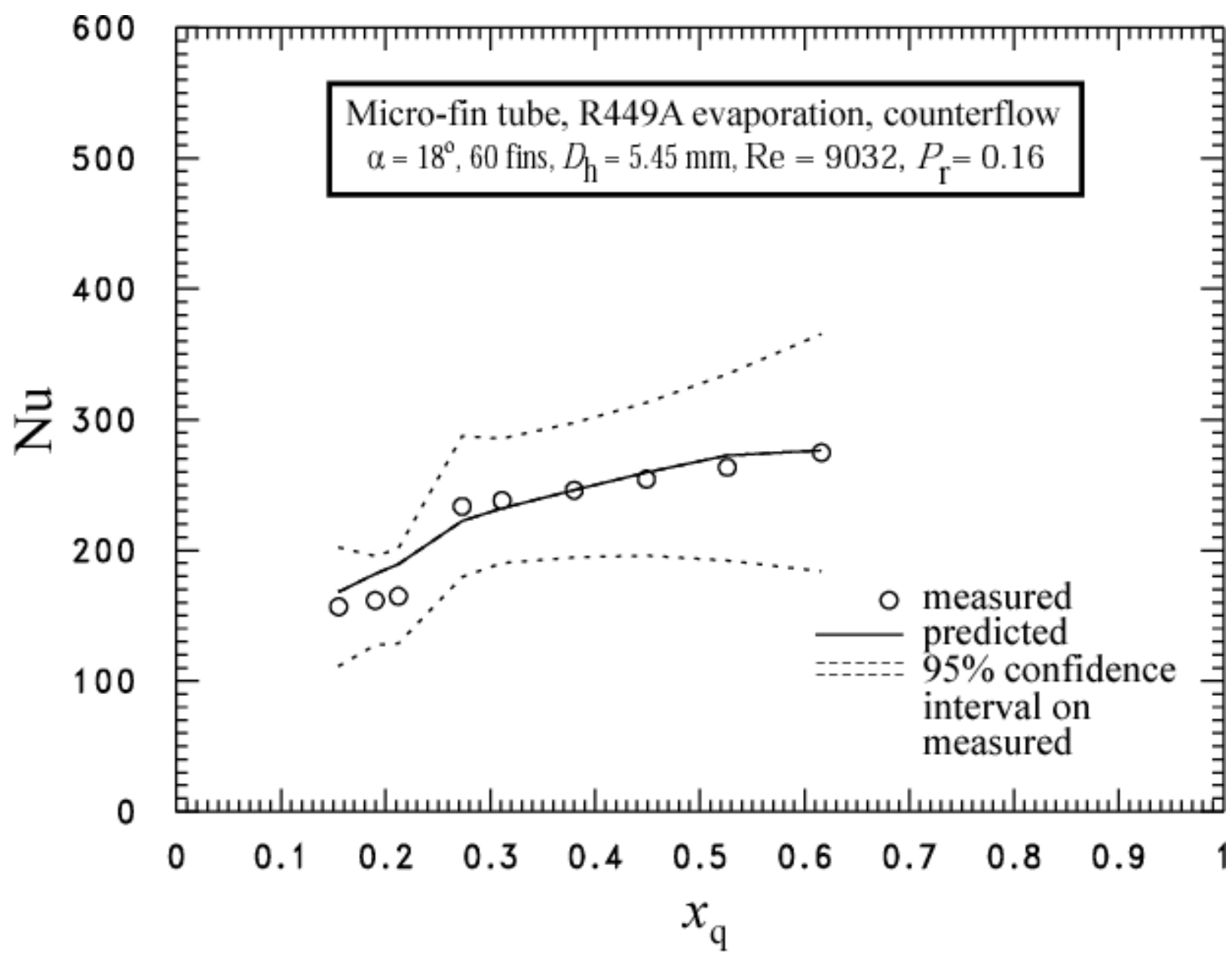

Figure 17 Comparison between measured Nusselt numbers and those predicted by eq. (5) for R449A 


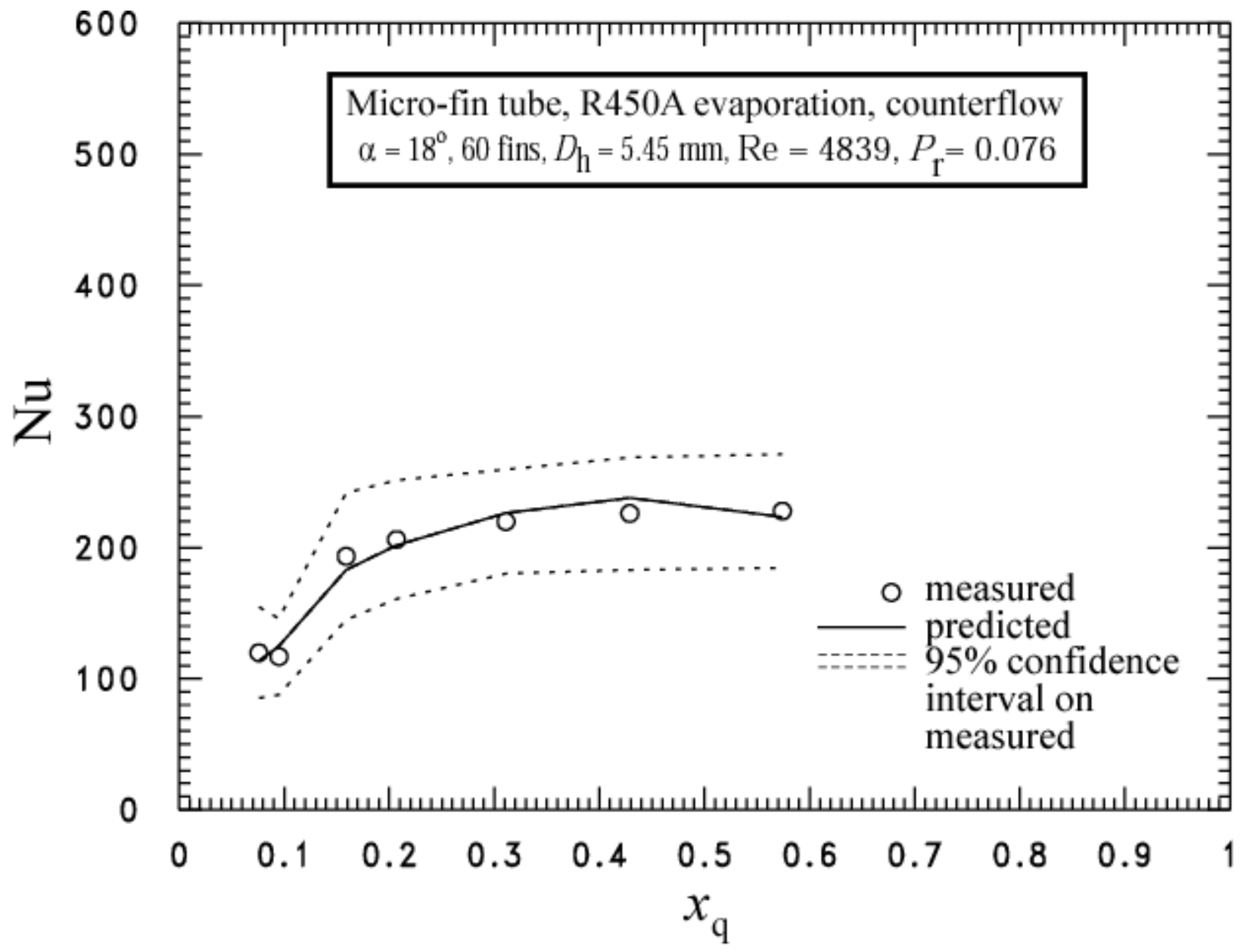

Figure 18 Comparison between measured Nusselt numbers and those predicted by eq. (5) for R450A 


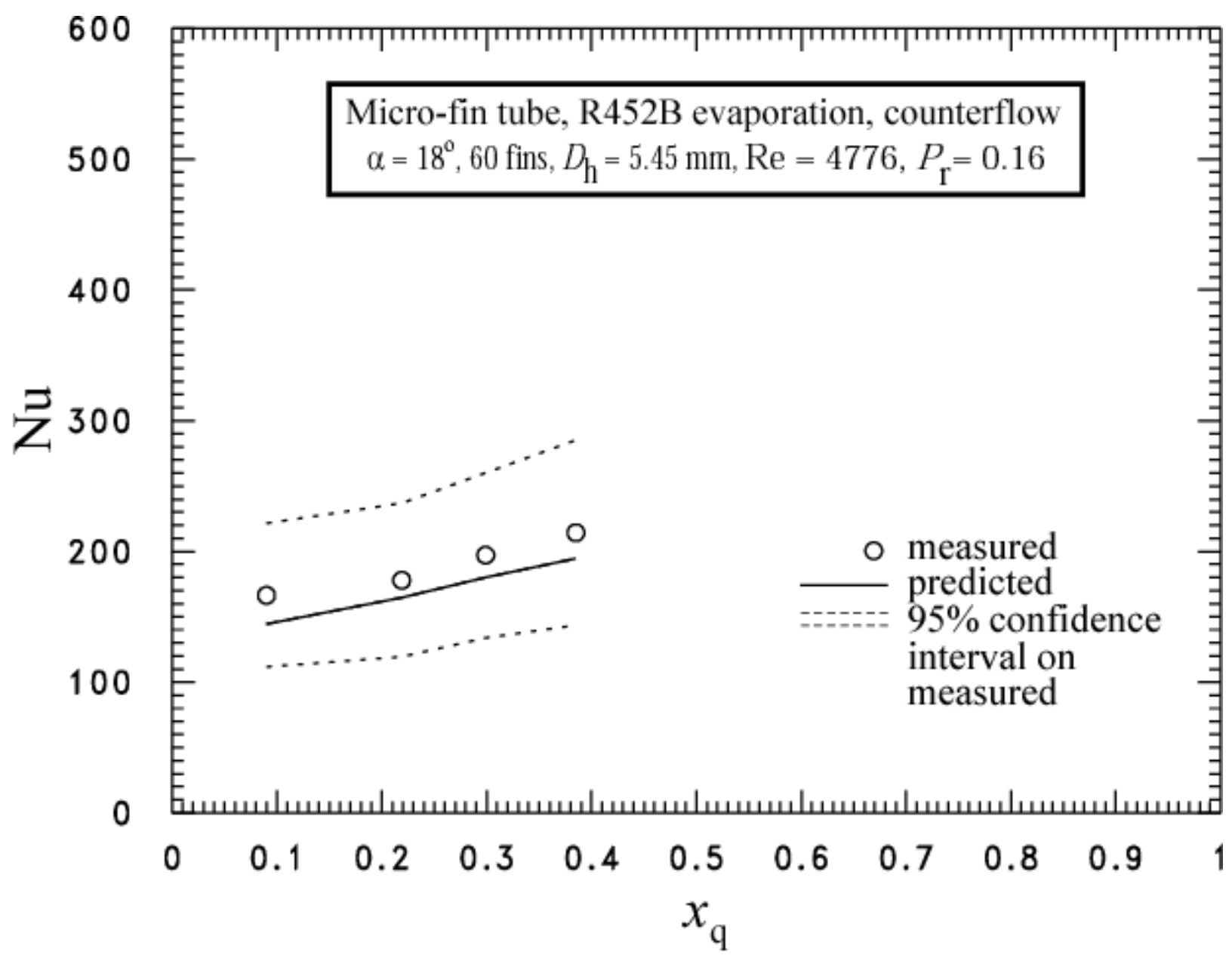

Figure 19 Comparison between measured Nusselt numbers and those predicted by eq. (5) for R452B 


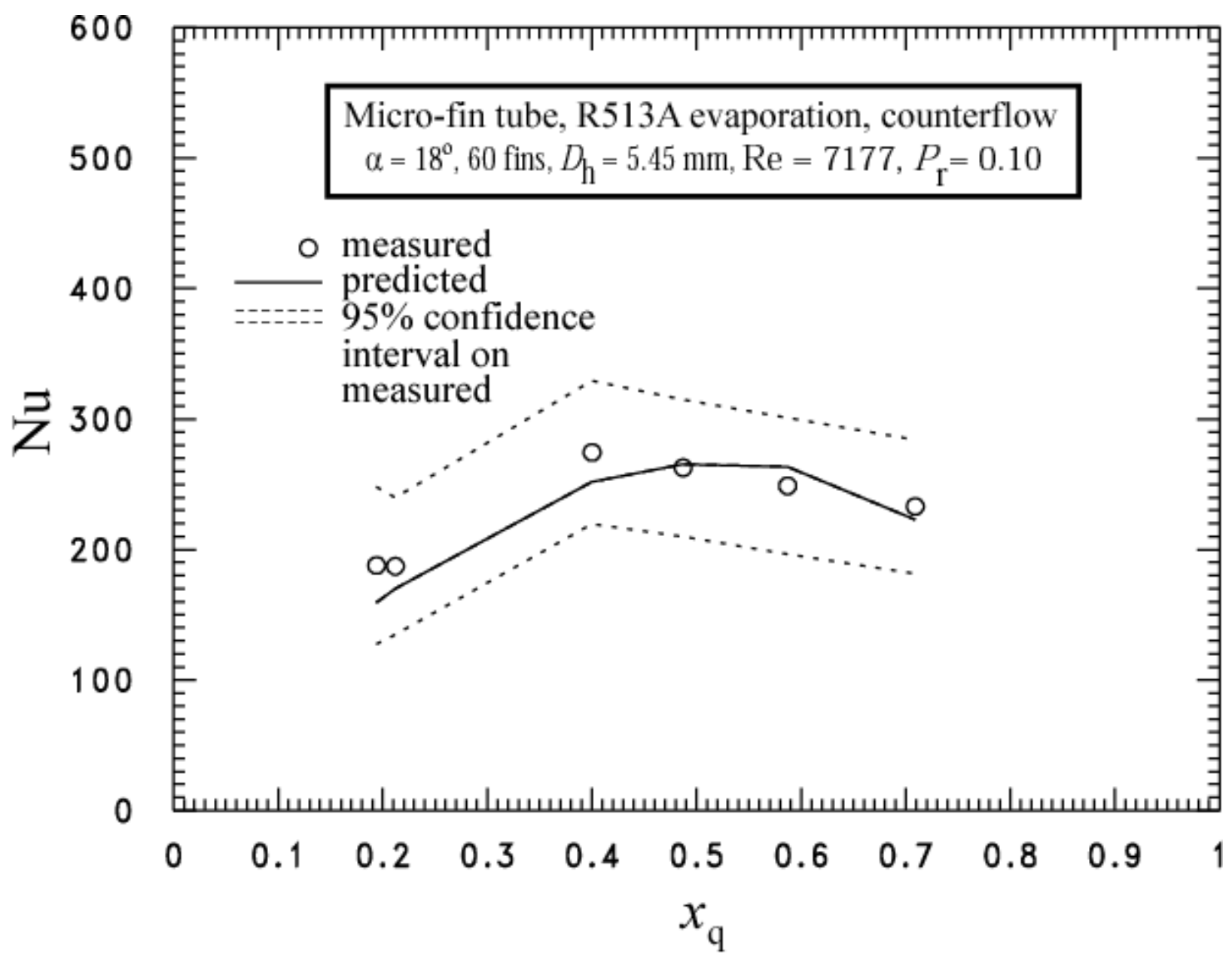

Figure 20 Comparison between measured Nusselt numbers and those predicted by eq. (5) for R513A 


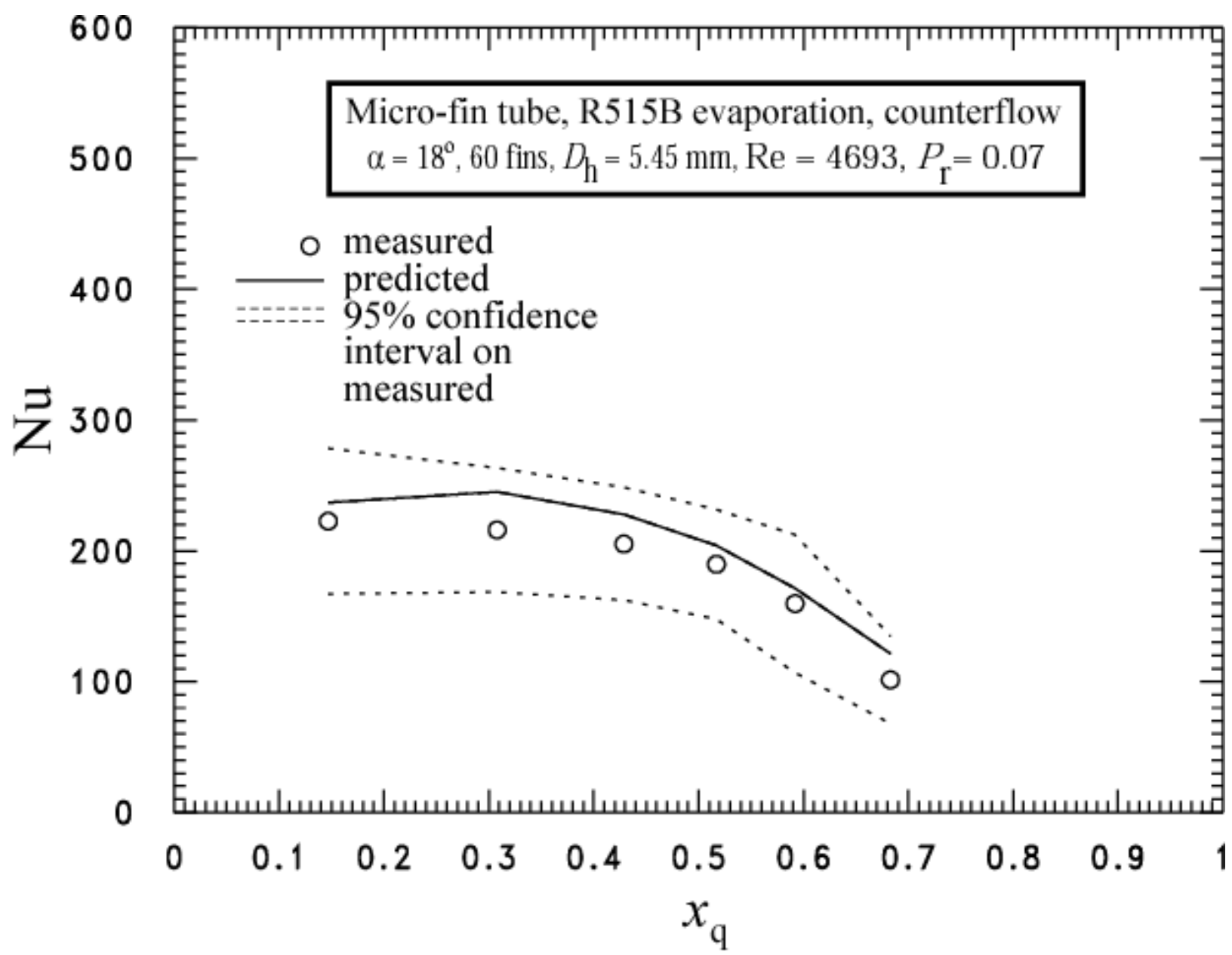

Figure 21 Comparison between measured Nusselt numbers and those predicted by eq. (5) for R515B 


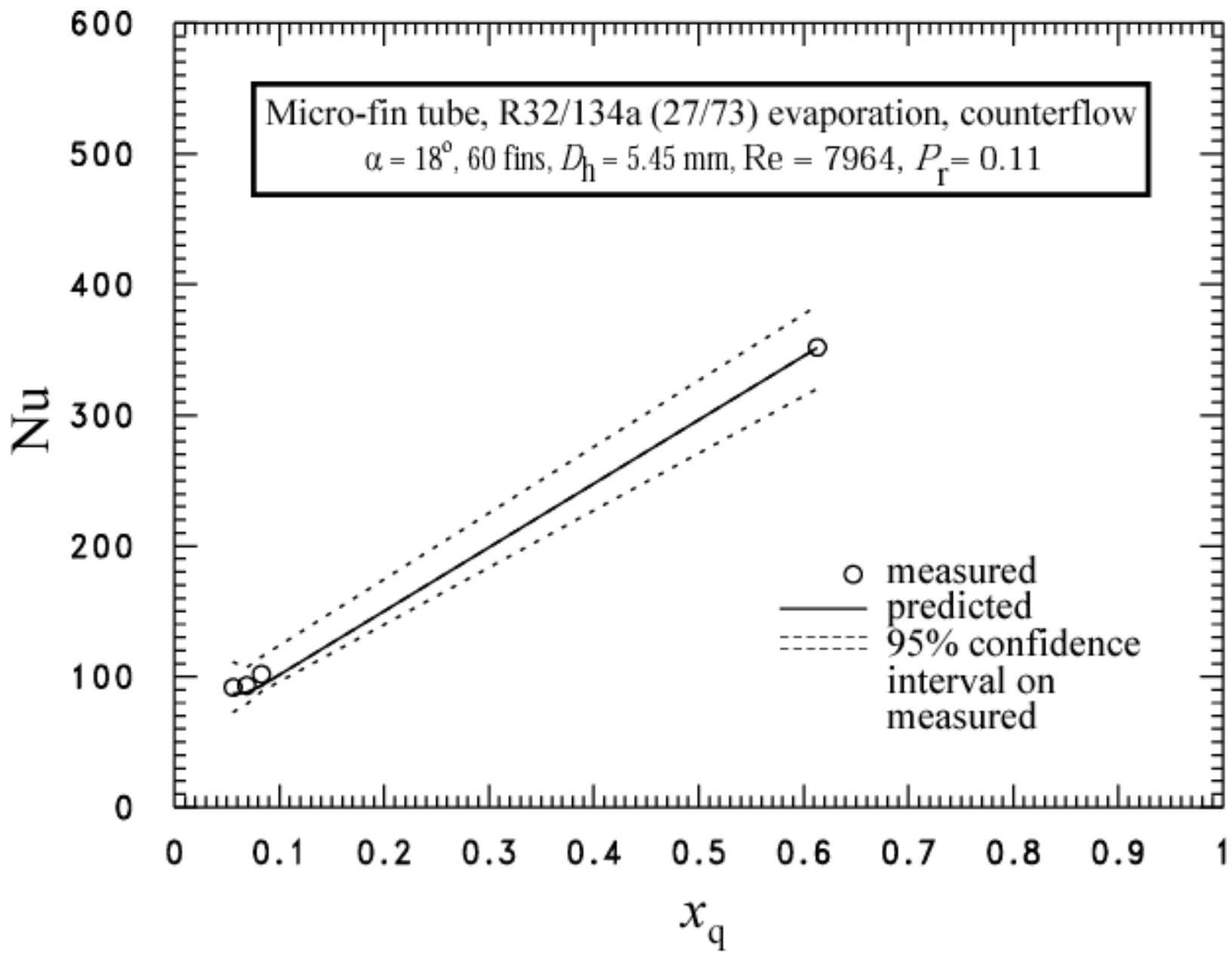

Figure 22 Comparison between measured Nusselt numbers and those predicted by eq. (5) for R32/R134a (27/73) 
Table 1 Median estimated $95 \%$ relative expanded uncertainties for measurements $(U)$

\begin{tabular}{||c|c|c|c||}
\hline Parameter & Minimum & Maximum & $U \%$ \\
\hline$G_{\mathrm{r}}\left[\mathrm{kg} \mathrm{m}^{-2} \cdot \mathrm{s}^{-1}\right]$ & 96 & 529 & 2.0 \\
\hline$T_{\mathrm{s}}[\mathrm{K}]$ & 273.8 & 281.8 & $0.1(0.3 \mathrm{~K})$ \\
\hline$P[\mathrm{kPa}]$ & 273 & 369 & 1.5 \\
\hline$T_{\mathrm{w}}[\mathrm{K}]$ & 276.1 & 285.0 & $0.1(0.4 \mathrm{~K})$ \\
\hline$\dot{m}_{f}\left[\mathrm{~kg} \mathrm{~s}^{-1}\right]$ & 0.006 & 0.032 & 2.0 \\
\hline$T_{\mathrm{f}}[\mathrm{K}]$ & 278.3 & 320.8 & 0.1 \\
\hline$P_{\mathrm{f}}[\mathrm{kPa}]$ & 200 & 110 & 1.0 \\
\hline$q^{\prime \prime}\left[\mathrm{kW} \mathrm{m}{ }^{-2}\right]$ & 0.7 & 43.8 & 15 \\
\hline$\left(T_{\mathrm{d}}-T_{\mathrm{b}}\right) / T_{\mathrm{b}}$ & 0 & 0.023 & 3.0 \\
\hline $\mathrm{Nu}$ & 1 & 720 & 20 \\
\hline $\mathrm{Re}$ & 2100 & 13300 & 4.0 \\
\hline $\mathrm{Bo}$ & $6 \times 10^{-7}$ & $6 \times 10^{-4}$ & 16.0 \\
\hline $\mathrm{Pr}$ & 2.1 & 4.2 & 2.0 \\
\hline$P_{\mathrm{s}} / P_{\mathrm{c}}$ & 0.06 & 0.19 & 2.0 \\
\hline$x_{\mathrm{q}}$ & 0.02 & 0.87 & 8.0 \\
\hline$\Delta T_{\mathrm{s}}[\mathrm{K}]$ & 0.15 & 31.15 & $0.44 \mathrm{~K}$ \\
\hline
\end{tabular}


Table 2 Representative properties from REFPROP (Lemmon et al. 2018)

\begin{tabular}{|c|c|c|c|c|c|c|c|c|c|c|}
\hline \multirow{2}{*}{$\begin{array}{l}\text { Test } \\
\text { fluid }\end{array}$} & \multicolumn{10}{|c|}{ Evaluated at $T_{\mathrm{s}}=277.6 \mathrm{~K}$} \\
\hline & $\begin{array}{c}T_{\mathrm{d}}-T_{\mathrm{b}} \\
(\mathrm{K})\end{array}$ & 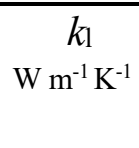 & $\operatorname{Pr}$ & $\begin{array}{c}\sigma \\
\mathrm{mN} \mathrm{m}^{-1}\end{array}$ & $\begin{array}{c}\rho_{\mathrm{l}} \\
\left(\mathrm{kg} \mathrm{m}^{-3}\right)\end{array}$ & $\begin{array}{c}\rho_{\mathrm{V}} \\
\left(\mathrm{kg} \mathrm{m}^{-3}\right)\end{array}$ & $\begin{array}{c}{\left[P_{\mathrm{s}}\right]_{x \mathrm{q}=0}} \\
(\mathrm{kPa})\end{array}$ & $\begin{array}{c}c_{\mathrm{p}} \\
\left(\mathrm{J} \mathrm{kg} \mathrm{K}^{-1} \mathrm{~K}^{-1}\right)\end{array}$ & $\begin{array}{c}i_{\mathrm{fg}} \\
\left(\mathrm{kJ} \mathrm{kg}^{-1}\right)\end{array}$ & $\begin{array}{c}\mu l \\
(\mu \mathrm{Pa} s)\end{array}$ \\
\hline R22 & 0.000 & 0.092 & 2.63 & 11.1 & 1265.9 & 24.4 & 575.9 & 1182 & 201.33 & 205.53 \\
\hline $\mathrm{R} 32$ & 0.000 & 0.142 & 1.79 & 10.2 & 1039.3 & 25.5 & 938.3 & 1771 & 308.04 & 143.06 \\
\hline R125 & 0.000 & 0.068 & 3.59 & 6.4 & 1298.3 & 48.6 & 772.2 & 1275 & 129.51 & 190.93 \\
\hline $\mathrm{R} 134 \mathrm{a}$ & 0.000 & 0.090 & 3.78 & 10.8 & 1279.6 & 16.9 & 344.2 & 1354 & 195.09 & 251.54 \\
\hline R1234yf & 0.000 & 0.070 & 3.63 & 8.8 & 1161.8 & 20.4 & 367.5 & 1306 & 160.32 & 194.27 \\
\hline R1234ze(E) & 0.000 & 0.081 & 4.04 & 11.7 & 1226.7 & 13.7 & 255.2 & 1329 & 181.25 & 247.48 \\
\hline $\mathrm{R} 407 \mathrm{C}$ & 6.013 & 0.094 & 3.04 & 9.4 & 1219.4 & 26.4 & 656.7 & 1433 & 212.50 & 199.11 \\
\hline $\mathrm{R} 410 \mathrm{~B}$ & 0.150 & 0.097 & 2.43 & 8.0 & 1164.5 & 35.8 & 918.0 & 1521 & 212.36 & 155.03 \\
\hline $\mathrm{R} 448 \mathrm{~A}$ & 5.552 & 0.091 & 2.83 & 8.9 & 1180.7 & 28.8 & 717.4 & 1441 & 207.93 & 178.40 \\
\hline R449A & 5.153 & 0.090 & 2.87 & 8.7 & 1180.6 & 28.8 & 706.0 & 1436 & 205.59 & 179.28 \\
\hline $\mathrm{R} 450 \mathrm{~A}$ & 0.640 & 0.084 & 3.89 & 11.2 & 1245.4 & 15.7 & 305.0 & 1339 & 186.54 & 245.39 \\
\hline R452B & 1.137 & 0.116 & 2.05 & 9.2 & 1075.8 & 28.0 & 884.4 & 1636 & 261.49 & 145.74 \\
\hline R513A & 0.015 & 0.078 & 3.65 & 9.5 & 1206.9 & 20.1 & 379.4 & 1329 & 172.28 & 212.68 \\
\hline R515B & 0.019 & 0.080 & 4.10 & 11.60 & 1245.8 & 14.0 & 253.5 & 1310 & 176.50 & 251.19 \\
\hline $32 / 134 a^{3}$ & 6.262 & 0.103 & 2.87 & 10.40 & 1194.0 & 20.9 & 609.1 & 1477. & 252.82 & 200.19 \\
\hline $32 / 134 a^{4}$ & 6.190 & 0.102 & 2.94 & 10.50 & 1201.9 & 20.6 & 588.1 & 1465. & 248.86 & 204.16 \\
\hline
\end{tabular}

${ }^{3} \mathrm{R} 32 / \mathrm{R} 134 \mathrm{a}(27 / 73)$ mass fraction.

${ }^{4} \mathrm{R} 32 / \mathrm{R} 134 \mathrm{a}(30 / 70)$ mass fraction. 
Table 3 Effect of re-reduction of data with current REFPROP (Lemmon et al. 2018)

\begin{tabular}{||c|c|c|c||}
\hline $\begin{array}{c}\text { Test } \\
\text { fluid }\end{array}$ & Minimum \% & Maximum \% & Average \% \\
\hline R22 & 0.00 & 10.30 & 0.76 \\
\hline R32 & 0.00 & 0.86 & 0.32 \\
\hline R125 & 0.00 & 1.41 & 0.68 \\
\hline R134a & 0.00 & 1.02 & 0.15 \\
\hline R1234yf & 0.00 & 14.34 & 5.25 \\
\hline R1234ze(E) & 0.00 & 0.69 & 0.23 \\
\hline R407C & 0.23 & 39.62 & 20.54 \\
\hline R410B & 0.02 & 39.87 & 21.89 \\
\hline R448A & 0.00 & 0.84 & 0.62 \\
\hline R449A & 0.00 & 4.71 & 2.16 \\
\hline R450A & 0.24 & 4.3 & 0.5 \\
\hline R452B & 0.00 & 25.00 & 2.10 \\
\hline R513A & 0.00 & 0.00 & 0.00 \\
\hline R515B & 0.00 & 0.00 & 0.00 \\
\hline $32 / 134 a^{5}$ & 13.78 & 39.75 & 31.33 \\
\hline $32 / 134 a^{6}$ & 28.11 & 39.99 & \\
\hline
\end{tabular}

${ }^{5} \mathrm{R} 32 / \mathrm{R} 134 \mathrm{a}(27 / 73)$ mass fraction.

${ }^{6} \mathrm{R} 32 / \mathrm{R} 134 \mathrm{a}(30 / 70)$ mass fraction. 